University of Wollongong

Research Online

Faculty of Engineering and Information

Faculty of Engineering and Information

Sciences - Papers: Part A

Sciences

2017

\title{
Hybrid model predictive control of a residential HVAC system with on-site thermal energy generation and storage
}

Massimo Fiorentini

University of Wollongong, massimo@uow.edu.au

Josh Wall

CSIRO

Zhenjun Ma

University of Wollongong, zhenjun@uow.edu.au

Julio H. Braslavsky

CSIRO, julio.braslavsky@csiro.au

Paul Cooper

University of Wollongong, pcooper@uow.edu.au

Follow this and additional works at: https://ro.uow.edu.au/eispapers

Part of the Engineering Commons, and the Science and Technology Studies Commons

Research Online is the open access institutional repository for the University of Wollongong. For further information contact the UOW Library: research-pubs@uow.edu.au 


\title{
Hybrid model predictive control of a residential HVAC system with on-site thermal energy generation and storage
}

\begin{abstract}
This paper describes the development, implementation and experimental investigation of a Hybrid Model Predictive Control (HMPC) strategy to control solar-assisted heating, ventilation and air-conditioning (HVAC) systems with on-site thermal energy generation and storage. A comprehensive approach to the thermal energy management of a residential building is presented to optimise the scheduling of the available thermal energy resources to meet a comfort objective. The system has a hybrid nature with both continuous variables and discrete, logic-driven operating modes. The proposed control strategy is organized in two hierarchical levels. At the high-level, an HMPC controller with a 24-h prediction horizon and a 1-h control step is used to select the operating mode of the HVAC system. At the low-level, each operating mode is optimised using a 1-h rolling prediction horizon with a 5-min control step. The proposed control strategy has been practically implemented on the Building Management and Control System (BMCS) of a Net Zero-Energy Solar Decathlon house. This house features a sophisticated HVAC system comprising of an air-based photovoltaic thermal (PVT) collector and a phase change material (PCM) thermal storage integrated with the air-handling unit (AHU) of a ducted reverse-cycle heat pump system. The simulation and experimental results demonstrated the high performance achievable using an HMPC approach to optimising complex multimode HVAC systems in residential buildings, illustrating efficient selection of the appropriate operating modes to optimally manage thermal energy of the house.
\end{abstract}

\section{Keywords}

thermal, on-site, system, hvac, residential, energy, control, storage, hybrid, model, predictive, generation

\section{Disciplines}

Engineering | Science and Technology Studies

\section{Publication Details}

Fiorentini, M., Wall, J., Ma, Z., Braslavsky, J. H. \& Cooper, P. (2017). Hybrid model predictive control of a residential HVAC system with on-site thermal energy generation and storage. Applied Energy, 187 465-479. 
1 Hybrid model predictive control of a residential HVAC system

\title{
with on-site thermal energy generation and storage
}

\author{
Massimo Fiorentini ${ }^{1 *}$, Josh Wall ${ }^{2}$, Zhenjun $\mathrm{Ma}^{1}$, Julio H. Braslavsky ${ }^{2}$, Paul Cooper ${ }^{1}$ \\ ${ }^{1}$ Sustainable Buildings Research Centre (SBRC), Faculty of Engineering and Information \\ Sciences, University of Wollongong, New South Wales, 2522, Australia \\ ${ }^{2}$ Commonwealth Scientific \& Industrial Research Organisation (CSIRO), CSIRO Energy \\ Flagship, Newcastle, New South Wales, NSW 2304, Australia \\ *Corresponding Author: massimo@uow.edu.au
}

Abstract: This paper describes the development, implementation and experimental investigation of a Hybrid Model Predictive Control (HMPC) strategy to control solar-assisted heating, ventilation and air-conditioning (HVAC) systems with on-site thermal energy generation and storage. A comprehensive approach to the thermal energy management of a residential building is presented to optimise the scheduling of the available thermal energy resources to meet a comfort objective. The system has a hybrid nature with both continuous variables and discrete, logic-driven operating modes. The proposed control strategy is organized in two hierarchical levels. At the high-level, an HMPC controller with a 24-hour prediction horizon and a 1-hour control step is used to select the operating mode of the HVAC system. At the low-level, each operating mode is optimised using a 1-hour rolling prediction horizon with a 5-minute control step. The proposed control strategy has been practically implemented on the Building Management and Control System (BMCS) of a Net Zero-Energy Solar Decathlon house. This house features a sophisticated HVAC system comprising of an air-based photovoltaic thermal (PVT) collector and a phase change material (PCM) thermal storage integrated with the air-handling unit (AHU) of a ducted reverse-cycle heat pump system. The simulation and experimental results demonstrated the high performance achievable using an HMPC approach to optimizing complex multimode HVAC 
systems in residential buildings, illustrating efficient selection of the appropriate operating modes to optimally manage thermal energy of the house.

28 Keywords: Hybrid model predictive control; Photovoltaic-thermal collectors; Phase change material thermal storage; Solar-assisted HVAC; System identification.

\section{$31 \quad$ Nomenclature}

$32 A_{i}=$ equivalent area of internal solar gains $\left[\mathrm{m}^{2}\right]$

$33 A_{e}=$ equivalent area of wall solar gains $\left[\mathrm{m}^{2}\right]$

$34 \quad c_{p}=$ specific heat of air $[\mathrm{J} / \mathrm{kg} \mathrm{K}]$

$35 C_{i}=$ indoor space equivalent capacitance $[\mathrm{kWh} / \mathrm{K}]$

$36 C_{e}=$ effective thermal capacitance of walls $[\mathrm{kWh} / \mathrm{K}]$

$37 \quad C_{p c m}=$ effective capacitance of PCM unit $[\mathrm{kWh} / \mathrm{K}]$

$38 \overline{C O P}=$ heat pump average coefficient of performance

$39 \delta_{m . .}=$ discrete Boolean variables for operating modes

$40 \delta_{m . .}=$ discrete Boolean variables for natural ventilation activation

$41 \delta_{h p}=$ discrete Boolean variable for heat pump activation

$42 \varepsilon=$ cost associated to thermal comfort constraint softening $\left[\mathrm{kW} /{ }^{\circ} \mathrm{C}\right]$

$43 \eta_{H P}=$ identifiable efficiency of the heat pump

$44 \quad \Phi_{i g}=$ internal loads $[\mathrm{kW}]$

$45 \Phi_{h p}=$ heat pump thermal generation $[\mathrm{kW}]$

$46 \quad \Phi_{P V T}=$ PVT system thermal generation $[\mathrm{kW}]$

$47 \quad \Phi_{P C M}=$ PCM unit thermal generation $[\mathrm{kW}]$

$48 \Psi=$ solar gains on building lumped capacitance surfaces $\left[\mathrm{kW} / \mathrm{m}^{2}\right]$

$49 \rho=$ air density $\left[\mathrm{kg} / \mathrm{m}^{3}\right]$

$50 R_{p c m}=$ equivalent PCM unit thermal resistance $[\mathrm{K} / \mathrm{kW}]$ 
$51 \quad R_{w}=$ equivalent half-wall resistance $[\mathrm{K} / \mathrm{kW}]$

$R_{v}=$ equivalent infiltration resistance, operable windows closed [K/kW]

$R_{v o}=$ equivalent infiltration resistance, operable windows open $[\mathrm{K} / \mathrm{kW}]$

$54 T_{a}=$ ambient temperature $\left[{ }^{\circ} \mathrm{C}\right]$

$55 T_{p c m, i}=$ PCM unit inlet air temperature $\left[{ }^{\circ} \mathrm{C}\right]$

$56 T_{p c m, o}=$ PCM unit outlet air temperature $\left[{ }^{\circ} \mathrm{C}\right]$

$57 T_{i}=$ average indoor temperature $\left[{ }^{\circ} \mathrm{C}\right]$

$58 \quad \bar{T}_{l}=$ indoor temperature upper boundary $\left[{ }^{\circ} \mathrm{C}\right]$

$59 \quad T_{i}=$ indoor temperature lower boundary $\left[{ }^{\circ} \mathrm{C}\right]$

$60 T_{p v t, o}=$ PVT outlet temperature $\left[{ }^{\circ} \mathrm{C}\right]$

$61 T_{\text {melt,b }}=$ PCM melting temperature, lower limit $\left[{ }^{\circ} \mathrm{C}\right]$

$62 T_{\text {melt,t }}=$ PCM melting temperature, upper limit $\left[{ }^{\circ} \mathrm{C}\right]$

$63 \dot{V}=$ air volume flow rate $\left[\mathrm{m}^{3} / \mathrm{s}\right]$

64

65

\section{Introduction}

Increasing energy efficiency in buildings has been recognized as one of the fastest and most cost-effective means to save energy and reduce greenhouse gas emissions, as the building sector accounts for approximately $40 \%$ of the world's energy demand [1]. A central piece in improving building energy efficiency and sustainability is the installation, commissioning and fine-tuning of efficient Heating, Ventilation and Air Conditioning (HVAC) systems and Building Management and Control Systems (BMCSs) [2].

The concept of Net-Zero Energy Buildings (NZEBs), which capture the high-level of energy usage performance required from buildings, has received growing attention as a research and technology driver, and has been extensively discussed in many energy policy forums (e.g. [1]). An instrumental methodology in achieving the goal of a NZEB is the embedding of 
optimal control strategies in building HVAC systems and BMCSs. These optimal control strategies can help match the building energy demand in face of weather-dependent energy generation and disturbances by efficiently integrating energy storage systems, which are now recognized as a proven demand management technology in building energy management.

However, the practical design and implementation of optimal control strategies that can efficiently integrate on-site energy generation and storage with a complex communication network between buildings, and to a smart grid, largely remains as a challenging problem [3]. Current industrial HVAC practice [4,5] is predominantly limited to the implementation of Rule-Based Control (RBC) and Proportional-Integral-Derivative (PID) control strategies, which have traditionally been reliable in the operation of building systems. However, such relatively simple classical control approaches cannot in general deal with the high performance requirements of modern buildings.

A proven advanced control strategy that can deal with such complex real-time optimal integration problem is Model Predictive Control (MPC). MPC is a well-established methodology in the control of complex interacting dynamic systems in the process industry, and has been receiving wide attention from the building control research community. In building systems, MPC has been applied to control the zone temperatures and building thermal mass [6-9], with numerous encouraging experimental results reported [10]. The formulation of dynamic models, a critical component of the MPC strategy, has been undertaken in a number of building studies [11,12], based on identifiable models and the use of model parameter identification techniques [13-16].

MPC has also been used to solve on-site generation and storage scheduling problems $[17,18]$ with continuous variables and discrete, logic-driven operating modes, generally leading to a mixed-integer programming problem to be solved $[19,20]$. This is commonly referred as Hybrid MPC (HMPC) [21-23]. 
101 In the area of residential buildings, implementation of MPC on a conventional heating system

102 showed a significant increase in the system energy efficiency [24]. A comprehensive

103 framework based on an MPC algorithm was presented by Di Giorgio and Liberati [25] to

104 optimally schedule electrical generation, storage and controllable demand in a house.

105 Many modern residential buildings, which are often aiming to achieve the Net Zero-Energy

106 target, implement renewable technologies on their HVAC systems, where the coordination of

107 solar thermal generation, thermal energy storage, conventional air conditioning systems and

108 operable windows must be optimally controlled to achieve efficiency and thermal comfort

109 objectives.

110 While quite extensive work has been undertaken in optimising temperature control or

111 scheduling electrical resources in buildings using the MPC framework, to the best of the

112 authors knowledge, there is a gap in current research in developing a comprehensive MPC

113 framework for this typology of HVAC systems at a residential scale, as well as a lack of

114 experimental demonstrations of their operation. Since these thermal energy resources are

115 highly weather-dependent, it is believed that these systems could strongly benefit from the

116 application of an MPC approach, through optimising the building thermal dynamics with the

117 management of the renewable and conventional thermal energy resources. As the

118 optimisation problem to be solved features a combination of continuous and discrete

119 dynamics, this will lead to the formulation of an HMPC controller. A preliminary

120 investigation on the application of an MPC strategy on the system studied in this paper

121 showed some promising results [26].

122 In this paper, an HMPC strategy is developed for optimising the operation of a solar-assisted

123 HVAC system, which includes Photovoltaic-thermal (PVT) collectors, an active PCM

124 thermal storage unit, a conventional reverse cycle air conditioning unit and operable windows

125 implemented in the 'Illawarra Flame' house, a net zero-energy retrofit house that won the 
126 Solar Decathlon China 2013 Competition. The system was designed for operation during

127 both winter and summer, using daytime solar radiation and night sky radiative cooling to

128 increase overall energy efficiency. To compute a near-optimal solution for this type of system

129 [27], the problem formulated as a Mixed Logical Dynamical (MLD) model can capture both

130 continuous and discrete dynamics, for which an HMPC controller is then developed.

131 In this study, an R-C model was utilised to represent the house dynamics and a system

132 identification of the key parameters was performed using the experimental data collected

133 from the house operation. A hierarchical HMPC control structure was implemented in Matlab

134 using the Hybrid Toolbox for Matlab [28]. A key objective of this study was to

135 experimentally demonstrate the implementation of this HMPC controller. A live

136 communication link between the Matlab script and the BMCS of the 'Illawarra Flame' house

137 allowed the deployment of the real-time controller and its testing on the real system. Section

1382 describes the case study HVAC system and its control system, followed by the description

139 of the grey-box building model and its identification in Section 3. The description of the

140 HVAC system models is provided in Section 4 and the MPC formulation is presented in

141 Section 5. The experimental results are reported in Section 6 and the conclusion is provided

142 in Section 7.

\section{2. Description of the case study HVAC System and Operating Modes}

144 The Team UOW Solar Decathlon house, its automated windows, and the schematic of its

145 HVAC system are shown in Figure 1. This HVAC system integrates a number of energy

146 components including a PVT system, a PCM thermal storage and a conventional air 147 conditioning system with an outdoor condenser unit and an indoor air-handling unit (AHU).

148 The PVT is used to generate the electricity and the low-grade thermal energy. The PCM

149 storage is used to store the low-grade thermal energy, which may then be used later for space

150 heating or cooling. The thermal storage is 'charged' by warm or cool air generated from the 
PVT either by winter daytime solar radiation or summer night-time sky radiative cooling, respectively.
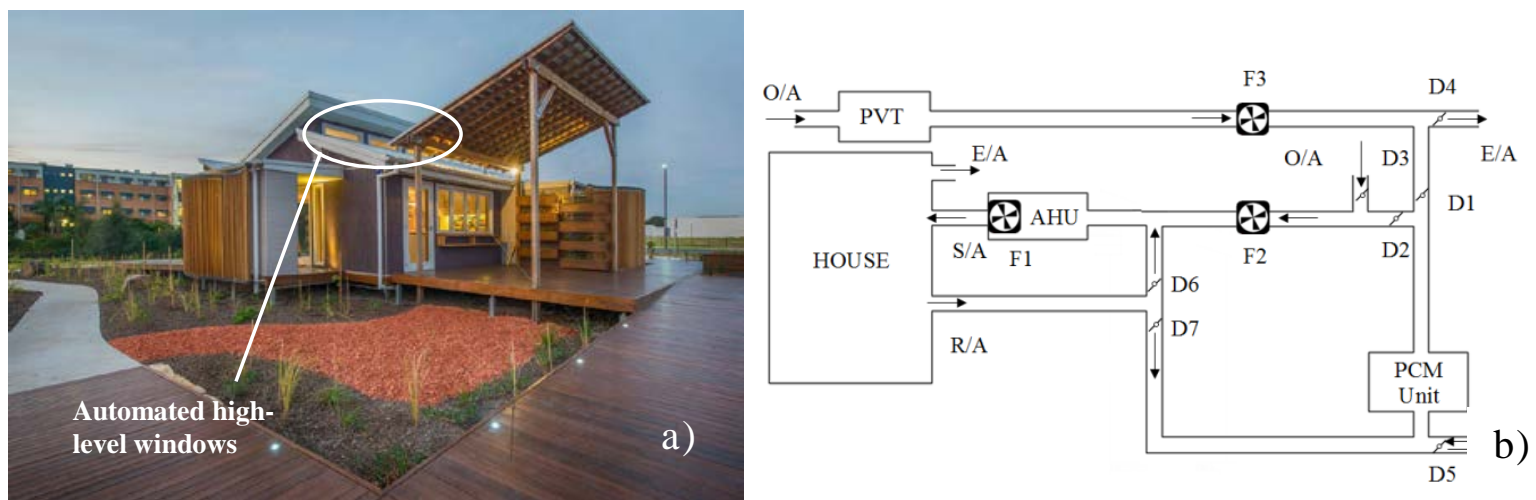

Figure 1: a) Team UOW Solar Decathlon house and its automated high-level windows and b)

Schematic of the solar-assisted HVAC system where the symbols represent the following: S/A supply air, O/A outside air, R/A return air, E/A exhaust air, $\mathrm{F}$ fan and $\mathrm{D}$ damper, respectively

There are five operating modes in this HVAC system, including three conditioning modes and two PVT modes, which are controlled through the BMCS specifically designed for the house.

\section{Conditioning modes}

162 Depending on the indoor conditions, the system can either work in the 'natural ventilation'

163 mode through automatically controlling the opening of the high-level windows, or work in

164 the mechanical heating mode or mechanical cooling mode. Selection of the three conditioning modes is determined based on the measured indoor and outdoor conditions.

In the mechanical heating and cooling modes, the system can operate in three different submodes, i.e. Direct Photovoltaic-Thermal Supply, Supply Air Preconditioned through Phase

Change Material, and Normal Heating and Cooling Mode.

\section{$169 \quad \underline{P V T \text { modes }}$}

170 If there is no interfering operating mode activated, the system can operate in two other modes, including PCM Charging and PVT Exhaust. A detailed description of the operating 
172 modes for the HVAC system can be found in [26]. The mode of PVT Exhaust is not

173 considered in this study.

\subsection{BMCS Description and System Integration}

175 The control system of the Illawarra Flame house was designed to accommodate the

176 objectives and constraints of the overall project, capable of controlling lighting systems,

177 operable windows and the complex HVAC system. The BMCS system designed is also to be capable of monitoring temperatures, energy consumption, electricity generation and flow rates, and can effectively report this information to the user via a graphical interface. For sourcing and project sponsoring reasons, the Australian manufacturer and supplier Clipsal, and its proprietary building management and control system C-Bus were used in the project. A supervisory BMCS (Tridium Niagara JACE) was integrated with the C-Bus system because of its capability to utilize various communication languages and the availability of drivers for common C-Bus units. This allowed a successful integration of the system components on for example Modbus and oBIX [30] networks. The JACE controller acts as a supervisor, informing C-Bus on which mode the system should operate and controlling the associated variables.

The JACE controller is also given the capability of overriding the local controller of the reverse-cycle air conditioning unit, utilising a Modbus gateway. This allows the control system to dynamically change the operation mode of the HVAC system, temperature set-

191 point and fan speed.

192 In order to easily implement the Hybrid MPC strategy, a machine running the Hybrid MPC

193 Matlab script is necessary, with the possibility to real-time override the JACE Niagara data 194 points. The Matlab script was interfaced to the JACE controller using an oBIX network 195 interface developed by the researchers from the Newcastle Energy Centre, Commonwealth 196 Scientific \& Industrial Research Organisation (CSIRO). This facilitates the implementation 
197 of virtually any desired control strategies in the house. The solver utilised for the optimisation

198 was Gurobi [31]. The HMPC controller was implemented on a commercial laptop computer

199 with an Intel ${ }^{\circledR}$ Core $^{\mathrm{TM}}$ i5 Processor $(2.7 \mathrm{GHz})$.

\subsection{Control Chain Structure}

201 Given the complexity of the problem to be solved, the HMPC control strategy was divided

202 into a high-level HMPC controller and multiple low-level HMPC controllers. The

203 information collected from the weather station is used for the weather forecast and the

204 prediction of the future PVT outlet temperature and its potential useful thermal generation

205 together with the system states, which are then used to compute the optimal control action

206 generated by the HMPC. The first set of actions from the optimal control sequence is then

207 sent to the BMCS to control the individual components and HVAC equipment.

208 The objective of the high-level HMPC is to compute the optimal sequence of the operating modes, using a control step of 1 hour and a prediction horizon of 24 hours.

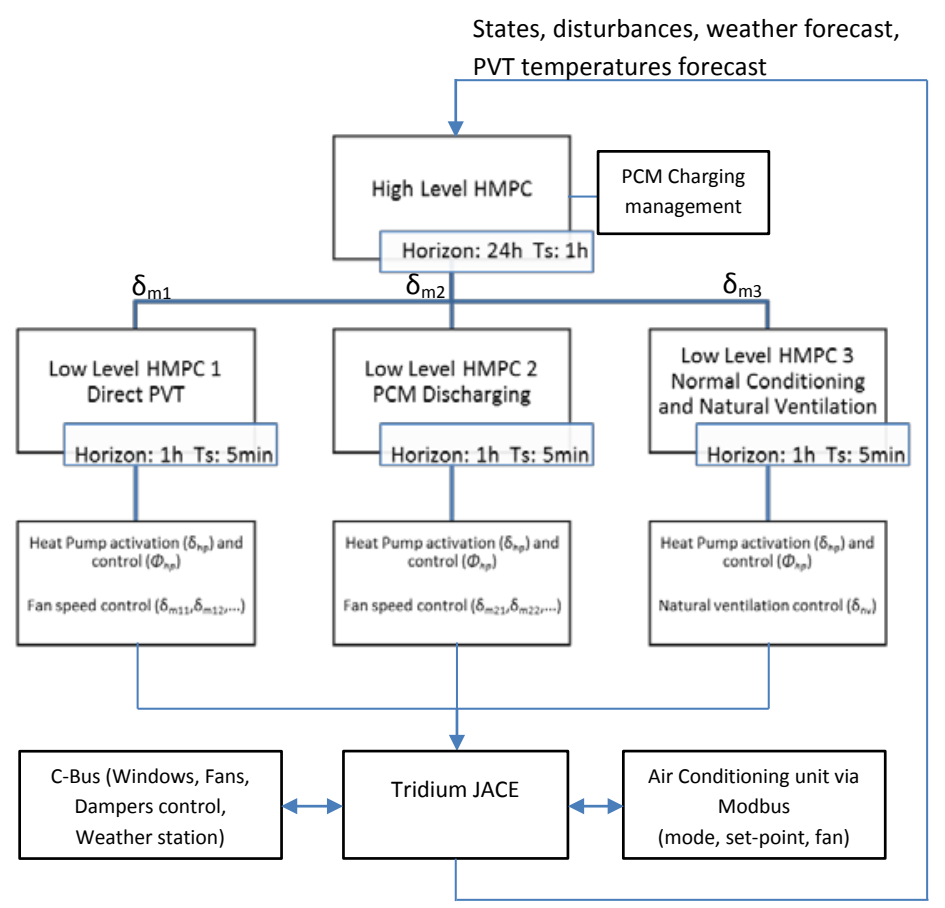

Figure 2: Control chain structure: the high-level controller selects the Conditioning mode and manages the PCM Charging mode and; the low-level controllers optimise the Conditioning mode and 
214 Once the high-level HMPC has selected the operating mode for the next hour, the 215 corresponding low-level HMPC controller is then activated (Figure 2). The objective of each

216 low-level HMPC controller is to optimise the selected operating mode for the time period of 217 concern, considering the range of the fan speeds that can be utilized for the PVT and PCM 218 storage, for example. The low-level HMPC computes the optimal solution with a control step 219 of 5 minutes and a prediction horizon of 1 hour. Once the optimal sequence of control actions has been computed, the first set of the actions is then sent to the JACE controller and applied to control the operation of the HVAC system (Figure 2).

\subsection{Measurement Instrumentation}

The weather conditions, including ambient temperature, solar radiation, and wind speed and direction, were monitored using a Davis Vantage Pro II Weather station and integrated through an RS232 connection to the C-Bus and JACE control units. Air flow rate was monitored using Siemens QVM62.1 air velocity sensors, located at one-third of the duct diameter from the duct centreline. These sensors had a stated accuracy of $\pm 0.2 \mathrm{~m} / \mathrm{s}+3 \%$ of the measured values. The temperatures in the ductwork were measured using Clipsal C-Bus Digital Temperature Sensor Units 5104DTSI with a stated accuracy of $\pm 0.5^{\circ} \mathrm{C}$ in the temperature range of $-10-80^{\circ} \mathrm{C}$.

\section{Building Modelling and System Identification}

The HMPC control strategy is developed based on a grey-box state-space model. The model, based on an R-C analogy, was developed in a similar manner to identifiable models available in the literature [13]. The parameters of this model were estimated using the datasets of the system in its various configurations, forcing the building with intermittent heating or cooling, and using the average temperature (from five temperature sensors) of the building as the thermal response. The building was therefore treated as a single thermal zone. The estimation of the building parameters was performed using a nonlinear least-square fitting method. 
239 The building was originally set to operate in two main modes, i.e. mechanical ventilation 240 when the high-level windows were completely closed and natural ventilation when the high-

241 level windows were fully open. In order to keep the system linear and easily identifiable, 242 natural ventilation was simply modelled with different building infiltration rates, i.e. $R_{v}$ when 243 the windows are closed and $R_{v o}$ when the windows are open. The R-C model of the building 244 is presented in Figure 3.

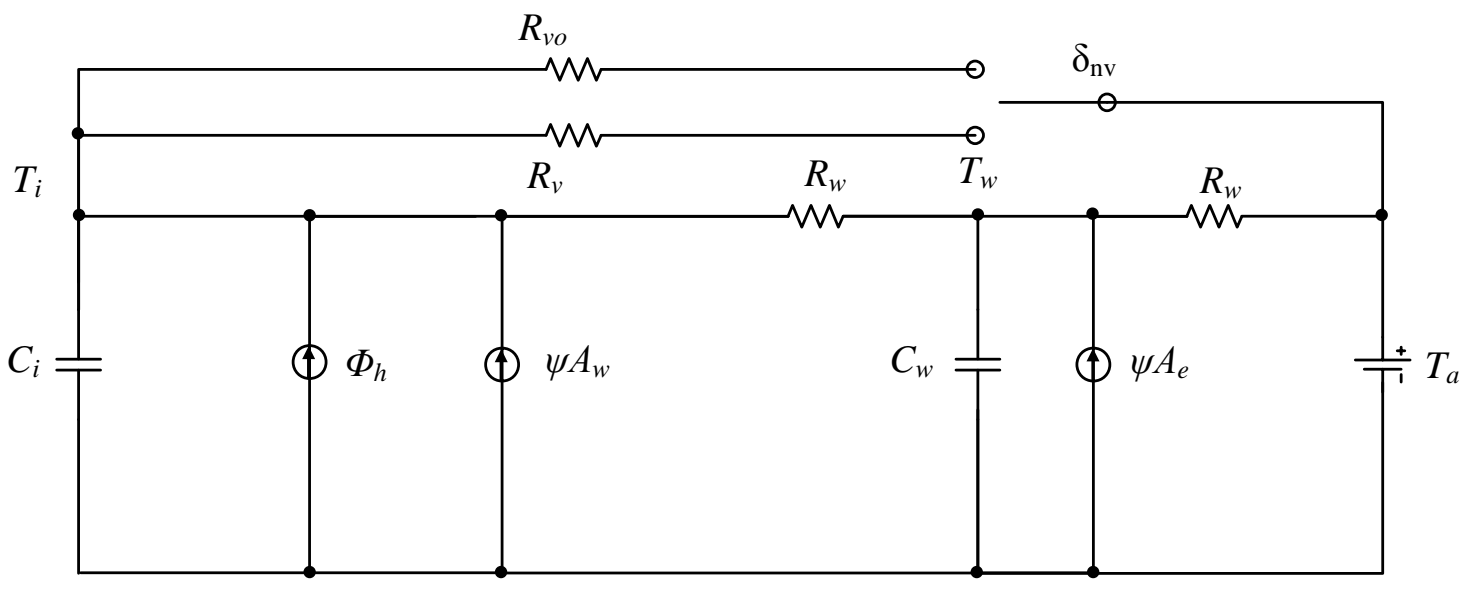

Figure 3: R-C representation of the building thermal system.

In this model, the state vector is $x=\left[T_{i}, T_{w}\right]^{\mathrm{T}}$, and the input vector is $u=\left[T_{a}, \Psi, \Phi_{h}\right]^{\mathrm{T}}$. The Boolean switch $\delta_{\mathrm{nv}}$ represents the opening of the windows.

The parameters subject to identification are the equivalent half wall resistance $R_{w}$, the

250 infiltration equivalent resistance with the windows closed $R_{v}$, the infiltration equivalent resistance with windows open $R_{v o}$, the equivalent internal capacitance $C_{i}$, the equivalent wall capacitance $C_{w}$, the equivalent windows area $A_{w}$, and the equivalent external wall area $A_{e}$. The system dynamics are described by the state-space equations of the R-C model illustrated in Figure 3.

\subsection{Identification of the House Parameters}

256 The model parameters, which represent the physical characteristics of the building, were identified using a number of datasets obtained from the real operation of the building, where the indoor temperature was forced to intermittently use the PVT system or the heat pump 
system. When the PVT system is active, the heating introduced to the building is calculated

$\Phi_{h_{-} P V T}=\rho \dot{V} c_{p}\left(T_{p v t, o}-T_{i}\right)$

262 When the heat pump system is active, the heating or cooling input of the heat pump, which is not directly measurable in the house setup, is considered to be proportional to the electrical

$\Phi_{h_{-} H P}=\eta_{H P} \overline{C O P} \Phi_{c, e l}$

In this study, a constant COP was considered to simplify the control problem, as the main

objective of the controller is to optimise the operation of the whole system.

Three input datasets were used for this identification, including the data with intermittent heating of the building with the heat pump, intermittent heating with the PVT system and cooling with the heat pump. An example is presented in Figure 4a, where the data set used and the responses of the building are presented, in the case of the heating with the heat-pump

a)

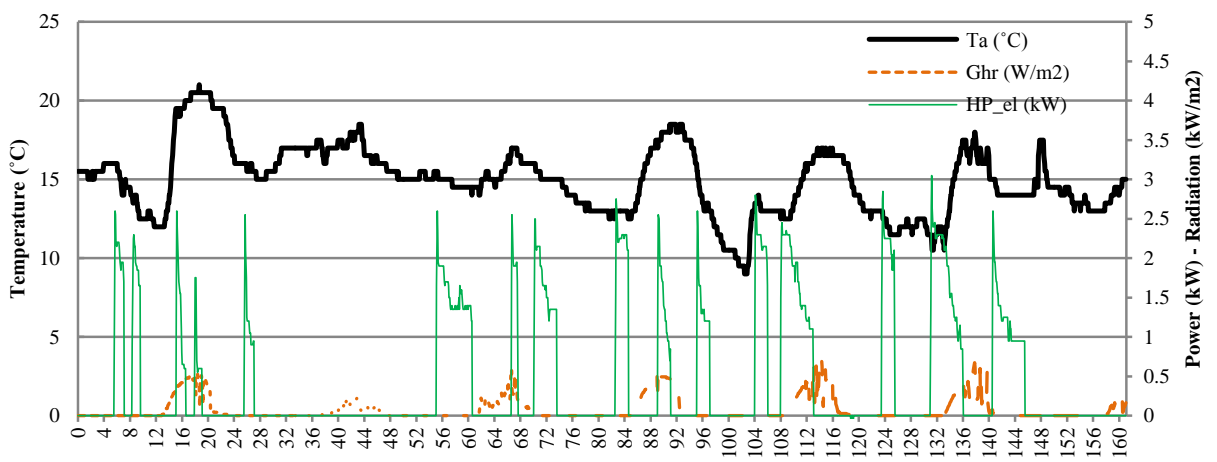

b)

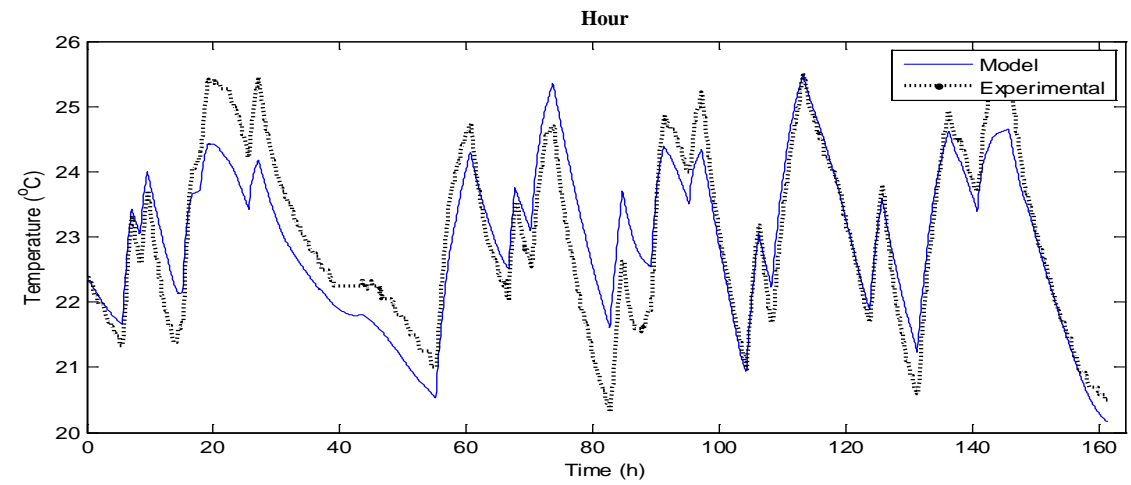

Figure 4: a) Identification input data heating with heat pump where HP_el is the electrical consumption and b) comparison between the data from the identified model and experimental data. 
277 As the proposed model is linear and time-invariant, Matlab’s System Identification Toolbox

278 in-built linear grey-box model estimation function [32] was used to fit the model parameters

279 using the experimental data.

280 To ensure that the values of the parameters identified are representative to the physical

281 lumped resistances and capacitances, the 'first guess' and boundary conditions were chosen

282 based on the design values of the Illawarra Flame house and commonly used minimum and maximum design values for each parameter. The values used are summarized in Table 1.

Table 1: Building parameters identification

\begin{tabular}{|c|c|c|c|c|}
\hline Parameter & First Guess & Lower Boundary & Upper Boundary & Identified Value \\
\hline$R_{w}(\mathrm{~K} / \mathrm{kW})$ & 7.90 & 2 & 20 & 6.54 \\
\hline$C_{i}(\mathrm{kWh} / \mathrm{K})$ & 0.76 & 0.06 & 5 & 3.39 \\
\hline$C_{w}(\mathrm{kWh} / \mathrm{K})$ & 22 & 1 & 40 & 6.72 \\
\hline$A_{e}\left(\mathrm{~m}^{2}\right)$ & 20 & 0.50 & 50 & 2.91 \\
\hline$A_{w}\left(\mathrm{~m}^{2}\right)$ & 1 & 0.01 & 5 & 1.15 \\
\hline$R_{V}(\mathrm{~K} / \mathrm{kW})$ & 7 & 1 & 20 & 7.62 \\
\hline$\eta_{H P}$ & 0.90 & 0.60 & 1 & 0.61 \\
\hline
\end{tabular}

285

286

The comparison between the measured response and the predicted response of the identified system under the three operation conditions is shown in Figure 4b.

The goodness of fit between the measured and the predicted outputs, widely used metric, defined in the Matlab System Identification Toolbox and [33], was 48.38, 54.15 and 57.48\% for the three different operation conditions, respectively.

The procedure was repeated for the natural ventilation mode to identify infiltration equivalent resistance with the windows open $R_{v o}$. To quantify this parameter, a test was conducted where the operable windows were kept fully open for a week, leaving the house free-running.

294 The boundaries for the parameter $R_{v o}$ were the same as for $R_{v}$ in the identification with the 295 windows closed. The identified infiltration equivalent resistance was 3.28, which is less than half of the infiltration resistance with the windows closed.

297 The goodness of fit between the both sets of the data was $47.09 \%$. The results of these 298 identifications can therefore be considered acceptable [11], considering that natural 
ventilation was also included, the limitations of the model (e.g. no influence of wind speed and direction on $R_{v o}$ ), the fact that multiple sources of thermal energy were used, the relatively limited inputs available from the measurements available to the building model, and the uncertainty associated with the experimental tests. While the statistical goodness of

303 fit of the identified model in the open loop is around $50 \%$, due to measurement noise and 304 disturbances, it is evident from Figure 4b that the model captures the dominant system dynamics, which is acceptable for control purposes. This observation is further supported by the closed-loop performance of the system, presented in Sections 6.1 and 6.2.

\section{Modelling of Solar-PVT Assisted HVAC System}

\subsection{PVT System and PVT Direct Supply}

309 The PVT collector studied in this paper consists of a number of thin-film PV panels mounted on a steel sheet flashing that is fixed onto the top of an existing sheet metal roof profile. This

311 system creates a cavity underneath the steel flashing through which the air exchanges heat 312 with the PVT panels.

313 To describe the heat transfer in the PVT, a steady-state model was employed to derive an 314 analytical solution to determine the PVT output [29]. The calculated outlet temperature of the 315 PVT is then used to calculate the heating that the PVT system can supply to the building using Eq. (1).

\subsection{PCM Thermal Storage unit and PCM Discharging}

318 The PCM thermal storage unit in the Solar Decathlon house was designed to exchange the

319 heat between the PCM and the air. It consists of PlusIce PCM bricks [34], which were placed vertically and spaced to create the channels for the air to flow through. The phase change temperature of the material used is $22^{\circ} \mathrm{C}$. The relationship used to describe the heat exchange in this PCM unit was presented in Ref. [29]. 
323 The heating that the PCM storage unit can supply to the building is determined by the 324 equation

$325 \quad \Phi_{h_{-} P C M}=\rho \dot{V} c_{p}\left(T_{p c m, o}-T_{i}\right)$

326 The equivalent thermal capacitance of the PCM unit was calculated through interpolating the differential scanning calorimeter test data measured at the Fraunhofer - Institut Für Solare Energiesysteme in Freiburg. The equivalent thermal capacitance was divided into three ranges, including the solid range $\left(C_{p c m, s}\right)$, the phase change range $\left(C_{p c m, c}\right)$, and the liquid range $330\left(C_{p c m, l}\right)$

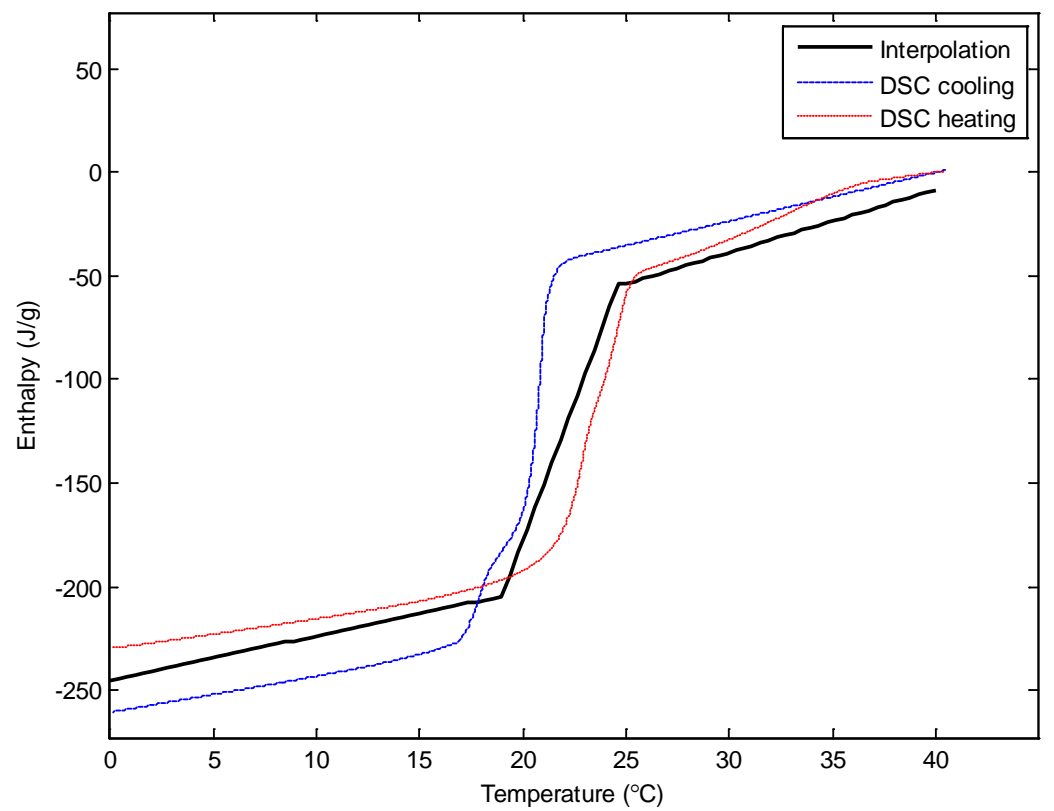

Figure 5: PCM equivalent thermal capacitance tested under a cooling and heating rate of $0.01 \mathrm{~K} / \mathrm{min}$ and a temperature range of $0-40^{\circ} \mathrm{C}$.

334 The equivalent capacitances of the PCM were $0.40,5.10$ and $0.57 \mathrm{kWh} /{ }^{\circ} \mathrm{C}$ for the solid range, 335 the phase change range and the liquid range, respectively.

336 The curve used for the implementation in the HMPC system is represented in Figure 5.

\section{$337 \quad$ 4.3 PCM Charging with PVT}

338 In the PCM charging with PVT, the total heat stored in the PCM unit can be determined by 339 the equation 


\section{$341 \quad 4.4$ Energy Consumption of the System Components}

342 The energy consumption of the system components in each operating mode is needed to compute the optimal solution of the controller to allocate a cost for each energy source.

344 Identification of the electrical consumption versus the air flow characteristics was the key aspect of the optimisation of the operating modes involving the PVT system or the PCM unit. The fit used was a $3^{\text {rd }}$ order polynomial of the form

$P_{\text {fan }}=\gamma_{D} \dot{\mathrm{V}}^{3}$

where the coefficient $\gamma_{D}$ is related to the system pressure losses and is calculated for each operating mode. The identification of these curves was presented in [35]. In this study, the consumption-airflow characteristic was considered at the discrete fan speed levels. The energy used by the heat pump is instantaneously measured and represented by $\Phi_{c, e l}$. The energy used in the natural ventilation mode is considered negligible and an infinitesimally small energy cost was associated to its operation.

\section{Hybrid Model Predictive Control Development}

The HVAC system presented in this study can operate in three different conditioning modes and one PVT mode. The switching between these operating modes would indicate a system model with a time-varying structure. The switching is also constrained, since some of these modes cannot operate simultaneously (e.g. PCM Charging and PCM Discharging modes) due to the physical constraints. Furthermore, the relationships between the PVT outlet temperature and the airflow rate are intrinsically nonlinear.

The switching and nonlinearity issues described above may be tackled by approaching the MPC problem formulation as an HMPC problem. HMPC can deal with both continuous and discrete dynamics, seeking optimal solutions by solving a mixed-integer programming problem. In particular, it is possible to describe this problem as a Mixed Logical Dynamical 
365 (MLD) system, in which the logic, dynamics and constraints are integrated as described in $366[27,28]$.

367 Taking into account the future samples of the reference vector and measured disturbance, the 368 prediction model has to be augmented with an additional linear model and treat the vector of

369 the future references and measured disturbances as the additional states [36].

370 Writing the problem as an MLD system with the discrete fan speeds removes the difficulty of 371 the aforementioned problems. Indeed, this results in a number of linear systems that can be 372 activated by appropriate Boolean variables. For each of these linear systems, the cost is fixed 373 at the energy used by the fan with the selected discrete speed step with the addition of the 374 consumption of the heat pump.

375 Given the number of Boolean variables and the requirement to compute the solution in a 376 relatively short time period (e.g. 5 minutes), the controller was divided into two levels: a 377 high-level controller that selects the operating mode every hour, and three low-level 378 controllers that optimize the operation of each operating mode every five minutes.

379 Each controller will have to minimise a cost function of the form $\min _{\{u, d, z\}_{0}^{N-1}} J\left(\{u, d, z\}_{0}^{N-1}, x(t)\right) \triangleq \sum_{k=1}^{N-1}\left\|Q_{x}\left(x(k)-x_{r}\right)\right\|_{p}+\sum_{k=1}^{N-1} \| Q_{u}(u(k)-$ $\left.u_{r}\right)\left\|_{p}+\sum_{k=1}^{N-1}\right\| Q_{z}\left(z(k)-z_{r}\right)\left\|_{p}+\sum_{k=1}^{N-1}\right\| Q_{y}\left(y(k)-y_{r}\right)\left\|_{p}+\right\| Q_{x N}\left(x(N \mid t)-x_{r}\right) \|_{p}$

382 The values and the parameters included in the cost function vary from controller to controller. 383 For this study, the infinity norm was used, with $p=\infty$. 


\subsection{High-Level Controller}

385 The main purpose of the high-level controller (Figure 6) is to determine the system operating mode under a given working condition. To maintain the problem relatively simple and minimise the number of Boolean optimisation variables, each mode was considered to operate at its nominal conditions (e.g. the fan speed for PVT Direct Supply and PCM

389 Charging mode is considered to be at $80 \%$ of the VSD range, corresponding to a flow rate of 390 approximately $300 \mathrm{~L} / \mathrm{s})$.

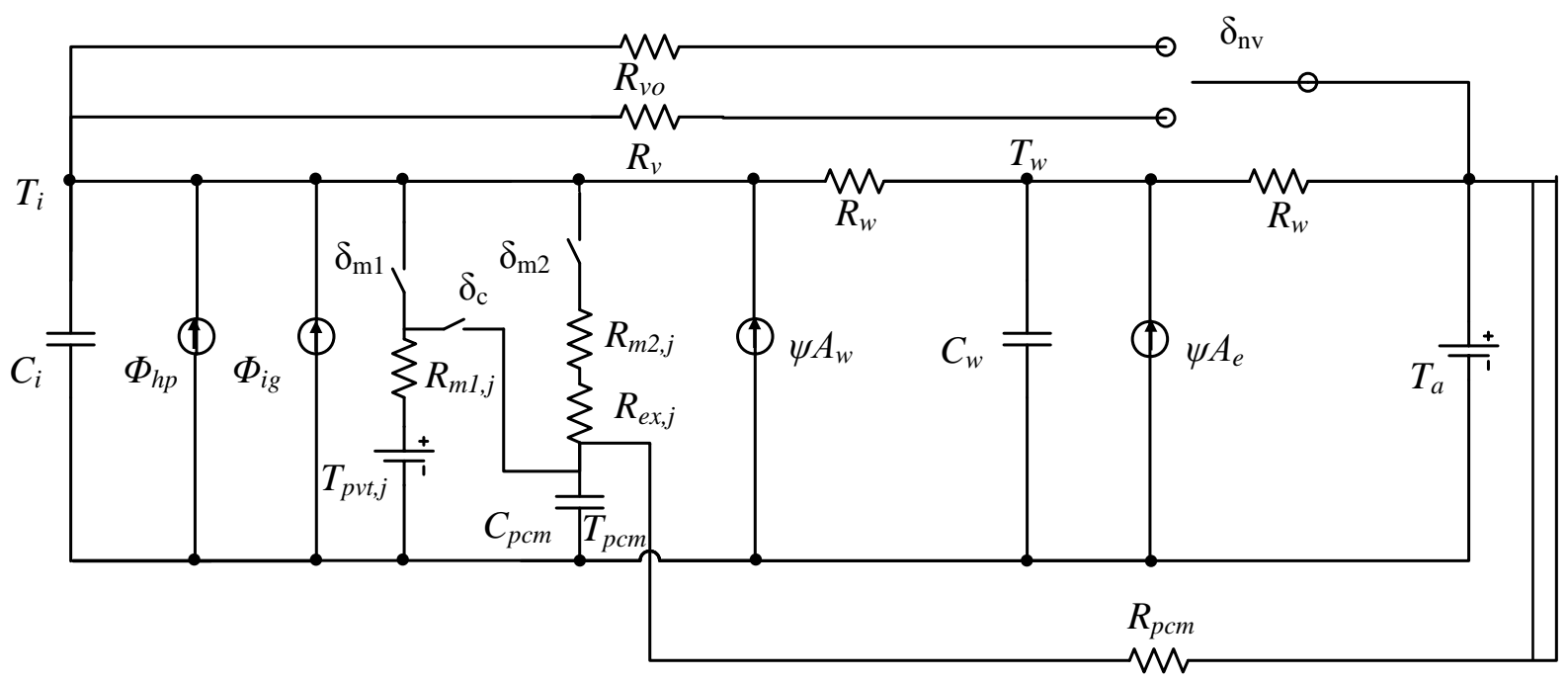
Figure 6: Schematic of High-level Controller system.

393 The states of the high-level controller, the measured disturbances and the controlled variables

394 are summarised in Table 2. The resistances $R_{m 1 j}$ and $R_{m 2 j}$ represent the delivered heating and 395 cooling to the building using the nominal air mass flow rates in PVT Direct Supply and PCM

396 Discharging modes, respectively. $R_{e x, j}$ represents the heat exchange rate of the PCM unit at 397 the nominal air flow rate. The equivalent PCM capacitance $C_{p c m}$ at each time step $k$ is defined 398 as

399

$$
C_{p c m}(k)=\left\{\begin{array}{lrr}
C_{p c m, s} & \text { if } & T_{p c m}<T_{\text {melt }, b} \\
C_{p c m, c} & \text { if } & T_{\text {melt }, b} \leq T_{p c m} \leq T_{\text {melt }, t} \\
C_{p c m, l} & \text { if } & T_{p c m}>T_{\text {melt }, t}
\end{array}\right.
$$


Once the high-level controller has selected the operating mode for the next hour, one of the

401 low-level controllers will be activated. The objective of this controller is to track the

402 reference temperature given by the high-level controller, using the next computed state of the

403 average indoor temperature $T_{i}$. The states of the low-level controllers, the measured

404 disturbances and the controlled variables are also summarised in Table 2.

Table 2: HMPC states, measured disturbances and controlled variables.

\begin{tabular}{|c|c|c|c|c|c|c|}
\hline Items & Parameters & Description & $\begin{array}{l}\text { High- } \\
\text { level }\end{array}$ & $\begin{array}{l}\text { Low- } \\
\text { level } 1\end{array}$ & $\begin{array}{l}\text { Low- } \\
\text { level } 2\end{array}$ & $\begin{array}{l}\text { Low- } \\
\text { level } 3\end{array}$ \\
\hline \multirow{3}{*}{ States } & $T_{i}$ & $\begin{array}{l}\text { average inside temperature } \\
\text { (measured) }\end{array}$ & $\checkmark$ & $\checkmark$ & $\checkmark$ & $\checkmark$ \\
\hline & $T_{w}$ & $\begin{array}{l}\text { equivalent wall temperature } \\
\text { (estimated) }\end{array}$ & $\checkmark$ & $\checkmark$ & $\checkmark$ & $\checkmark$ \\
\hline & $T_{p c m}$ & average PCM temperature (measured) & $\checkmark$ & $x$ & $\checkmark$ & $x$ \\
\hline \multirow{4}{*}{$\begin{array}{c}\text { Measured } \\
\text { disturbance }\end{array}$} & $T_{a}$ & ambient temperature & $\checkmark$ & $\checkmark$ & $\checkmark$ & $\checkmark$ \\
\hline & $\Psi$ & global horizontal radiation & $\checkmark$ & $\checkmark$ & $\checkmark$ & $\checkmark$ \\
\hline & $\Phi_{i g}$ & Internal loads & $\checkmark$ & $\checkmark$ & $\checkmark$ & $\checkmark$ \\
\hline & $T_{p v t, j}$ & $\begin{array}{l}\text { PVT calculated outlet temperature at } \\
\text { fan speed } j\end{array}$ & $\checkmark$ & $\checkmark$ & $x$ & $x$ \\
\hline \multirow{7}{*}{$\begin{array}{l}\text { Controlled } \\
\text { variable }\end{array}$} & $\varepsilon$ & $\begin{array}{l}\text { constraint softening on indoor } \\
\text { temperature }\end{array}$ & $\checkmark$ & $x$ & $x$ & $x$ \\
\hline & $\Phi_{\mathrm{hp}}$ & $\begin{array}{l}\text { thermal input to the building provided } \\
\text { by the heat pump }\end{array}$ & $\checkmark$ & $\checkmark$ & $\checkmark$ & $\checkmark$ \\
\hline & $\delta_{\mathrm{m} 1 \mathrm{j}}$ & $\begin{array}{l}\text { PVT Direct Supply (at fan speed } j \text { in } \\
\text { low-level controllers) }\end{array}$ & $\checkmark$ & $\checkmark$ & $x$ & $x$ \\
\hline & $\delta_{\mathrm{m} 2 \mathrm{j}}$ & $\begin{array}{c}\text { PCM Discharge Supply (at fan speed } \\
j \text { in low-level controllers) }\end{array}$ & $\checkmark$ & $x$ & $\checkmark$ & $x$ \\
\hline & $\delta_{\mathrm{c}}$ & PCM Charging mode & $\checkmark$ & $x$ & $x$ & $x$ \\
\hline & $\delta_{\mathrm{nv}}$ & Natural ventilation mode & $\checkmark$ & $x$ & $x$ & $\checkmark$ \\
\hline & $\delta_{\mathrm{hp}}$ & $\begin{array}{l}\text { Heat pump active (minimum heat } \\
\text { delivery) }\end{array}$ & $x$ & $\checkmark$ & $\checkmark$ & $\checkmark$ \\
\hline
\end{tabular}

407 The set of the constraints associated with the high-level controller are as follows:

- Two conflicting modes are not activated at the same time;

- The heat pump thermal input respects the physical limits of the real unit; and

- The comfort conditions are maintained, keeping the average indoor temperature in the defined comfort range. 
412 The limit of the air conditioning thermal capacity $\left(\Phi_{\mathrm{hp}}\right)$ is represented by $\left[\overline{\Phi_{h p}}, \underline{\Phi_{h p}}\right]$, and the

413 limits of the allowance for the temperature to go outside the comfort band $(\varepsilon)$ is represented

414 by $[\bar{\varepsilon}, \underline{\varepsilon}]$. The logical conditions are:

415

$\sim\left(\delta_{\mathrm{m} 2} \& \delta_{\mathrm{m} 1}\right), \sim\left(\delta_{\mathrm{m} 2} \& \delta_{\mathrm{nv}}\right), \sim\left(\delta_{\mathrm{m} 1} \& \delta_{\mathrm{nv}}\right), \sim\left(\delta_{\mathrm{m} 2} \& \delta_{\mathrm{c}}\right), \sim\left(\delta_{\mathrm{m} 1} \& \delta_{\mathrm{c}}\right), T_{i}<=\overline{T_{i}}+\varepsilon, T_{i}>=\underline{T_{i}}-\varepsilon$.

416 Where is the "not" condition and \& is the "and" condition.

417 5.2 Low-Level Controller 1 - Direct PVT and Normal Conditioning

418 Low-level controller 1 (Figure 7) is selected when the Boolean variable $\delta_{\mathrm{m} 1}$ of the high-level 419 controller is active. This controller sets the system in mechanical ventilation and operates the 420 PVT Direct Mode in conjunction with the operation of the heat pump. This controller can 421 select various Boolean variables corresponding to the discrete fan speed levels.

422

423

424

425

426

427

428

429

430

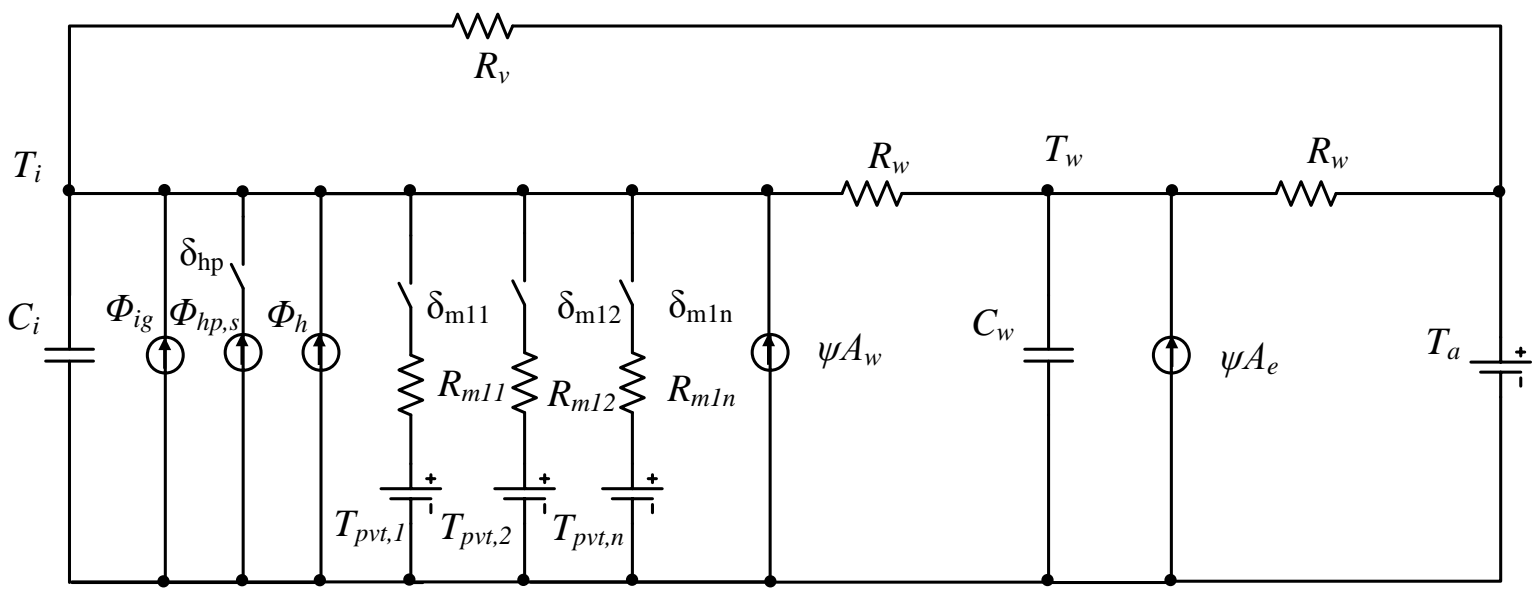

Figure 7: System schematic of low-level controller 1.

The PVT system can provide the thermal energy independently or can operate in conjunction with the heat pump (PVT Direct mode and PVT pre-heating/pre-cooling the air for the AHU). The heat pump can also operate without the PVT (Normal Conditioning mode).

The resistances $R_{m 11}, R_{m 12}, R_{m 1 n}$ represent the heating/cooling delivery to the building using the various air mass flow rates.

The set of the constraints associated to the low-level controller 1 are as follows:

- Two fan speeds are not activated at the same time; 
- The heat pump thermal input respects the physical limits of the real unit; and

- The comfort conditions are maintained, following the trajectory defined by the highlevel controller.

The limits of the air conditioning thermal capacity $\left(\Phi_{\mathrm{hp}}\right)$ are the same as that of the high-level controller. Logical conditions are:

$\sim\left(\delta_{\mathrm{m} 11} \& \delta_{\mathrm{m} 12}\right), \sim\left(\delta_{\mathrm{m} 11} \& \delta_{\mathrm{m} 1 \mathrm{n}}\right), \ldots, \sim\left(\delta_{\mathrm{m} 12} \& \delta_{\mathrm{m} 1 \mathrm{n}}\right), \sim\left(\delta_{\mathrm{hp}} \& \Phi_{h p} \neq 0\right) .$.

\subsection{Low-Level Controller 2 - PCM Discharging and Normal Conditioning}

Low-level controller 2 (Figure 8) is selected when the Boolean variable $\delta_{\mathrm{m} 2}$ of the high-level controller is active. This controller sets the system in mechanical ventilation and operates the PCM Discharging Mode in conjunction with the operation of the heat pump. This controller can select various Boolean variables that correspond to the discrete fan speed levels.

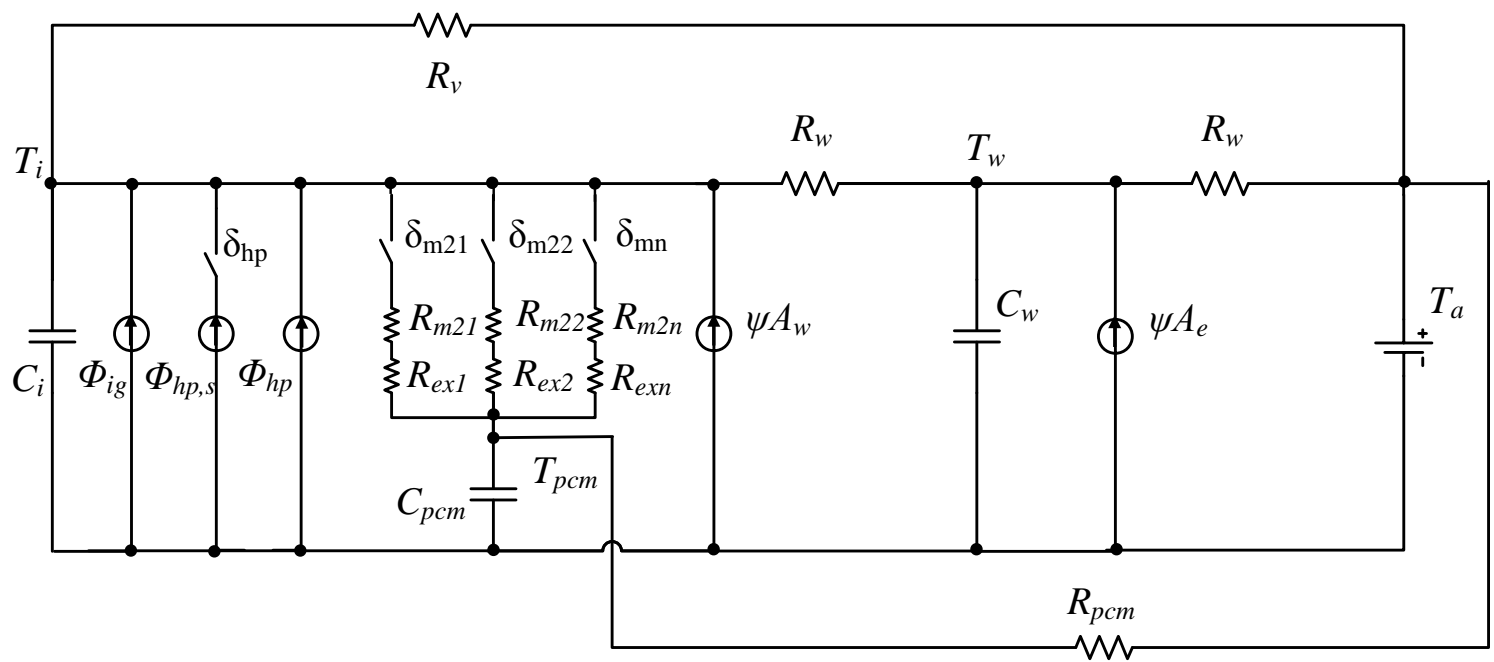

Figure 8: System schematic of low-level controller 2.

The resistances $R_{e x 1}, R_{e x 2}, R_{e x n}$ represent the heat exchange rate into the PCM unit corresponding to the various air flow rates and $R_{m 21}, R_{m 22}, R_{m 2 n}$ represent the heating and cooling delivery to the building using the various air mass flow rates.

The set of the constraints associated to the low-level controller 2 are similar to the ones of the low-level controller 1.

$\sim\left(\delta_{\mathrm{m} 21} \& \delta_{\mathrm{m} 22}\right), \sim\left(\delta_{\mathrm{m} 21} \& \delta_{\mathrm{m} 2 \mathrm{n}}\right), \ldots, \sim\left(\delta_{\mathrm{m} 22} \& \delta_{\mathrm{m} 2 \mathrm{n}}\right), \sim\left(\delta_{\mathrm{hp}} \& \Phi_{h p} \neq 0\right)$ 


\subsection{Low-Level Controller 3 - Natural Ventilation and Normal Conditioning}

451 Low-level controller 3 (Figure 9) is selected when neither the Boolean variable $\delta_{\mathrm{m} 1}$ nor $\delta_{\mathrm{m} 2}$ of 452 the high-level controller are active. This controller sets the mechanical ventilation system 453 Normal Conditioning Mode and operates the heat pump depending on the value of the 454 optimal thermal input $\Phi_{\mathrm{hp}}$ calculated at each control step, and operates the high-level operable windows of the house. This controller utilises two Boolean variables that correspond to the operation of the building in mechanical or natural ventilation and the activation of the heat pump.

458

459

460

461

462

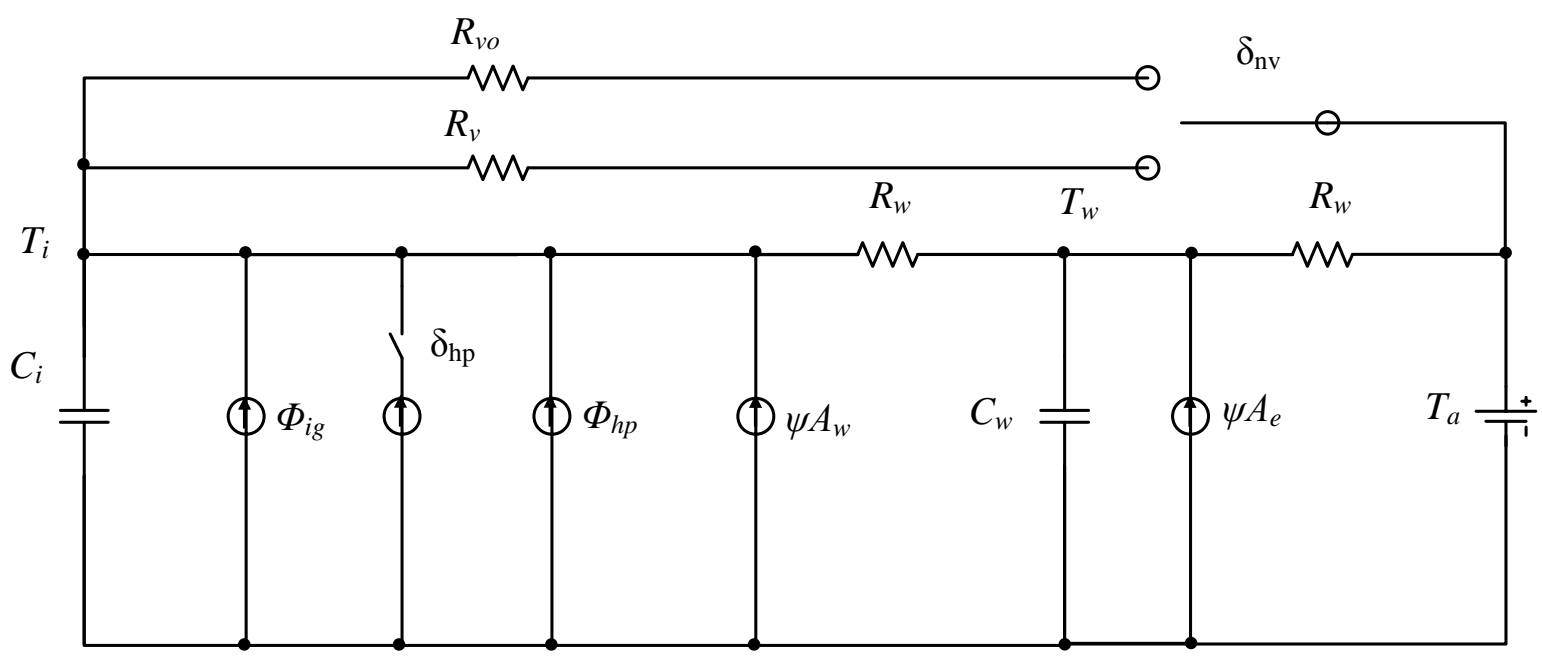

Figure 9: System schematic of low-level controller 3.

The set of the constraints associated to the low-level controller 3 are as follows:

- Natural ventilation and air conditioning are not to be activated at the same time;

- The heat pump thermal input respects the physical limits of the real unit; and

- The comfort conditions are maintained, following the trajectory defined by the highlevel controller.

The limits of the air conditioning thermal capacity $\left(\Phi_{\mathrm{hp}}\right)$ are the same as that of the high-level controller. The logical conditions are that natural ventilation and the air conditioning do not operate at the same time and the heat pump cannot provide additional heating if it is not switched on. 
$\sim\left(\delta_{\mathrm{hp}} \& \delta_{\mathrm{nv}}\right) ; \sim\left(\delta_{\mathrm{hp}} \& \Phi_{\mathrm{hp}} \neq 0\right)$.

470 Given the objective of the low-level controllers, it is possible that the controller will

471 intermittently heat and cool the building to follow a certain trajectory. To avoid this problem,

472 each low-level controller was developed in two versions, i.e. one only allows heating and the

473 other only allows cooling. The type of the controller used is dictated by the request for

474 heating or cooling by the high-level controller and for that hour the appropriate low-level 475 controller is selected.

\section{$476 \quad 5.5$ Weather Forecast}

477 In this paper, an adaptive weather-prediction model developed in [37] was used to forecast 478 external dry-bulb temperature and solar radiation over the 24 hours prediction horizon. These 479 predictions serve as the inputs to both the building model and the PVT analytical thermal 480 model.

481 Among the various approaches presented in [37], the Deterministic-Stochastic method was 482 adopted to predict both external dry-bulb temperature and solar radiation.

\section{Experimental and Simulation Results}

484 The experiments were conducted using the Illawarra Flame house at Innovation Campus, 485 Wollongong, in March and April 2015. The two tests were carried out using the HMPC 486 strategy presented in this paper, mainly in cooling dominated periods. In the first test, only mechanical ventilation was used, while in the second one natural ventilation was also 488 included. Tests were also conducted during the heating dominated periods, but the results are 489 not presented in order to avoid a lengthy paper. Difficulties in implementing the target $\mathrm{R}=3.0$ 490 insulation to the PCM storage unit could not be fully achieved, and therefore affected the 491 PCM heat loss. The HMPC strategy successfully controlled the system, despite the issues 492 with the real system. 
493 The tests were performed using a variable comfort band, which was considered as a variable

494 soft constraint for the average indoor temperature, where the upper boundary $\underline{T_{i}}$ and the

495 lower boundary $\overline{T_{i}}$ for the cooling and heating are defined as

$496 \quad \overline{T_{i}}(k)=\left\{\begin{array}{lr}24^{\circ} \mathrm{C} & \text { if } 9 \leq \operatorname{hour}(k) \leq 18, \\ 25.5^{\circ} \mathrm{C} & \text { otherwise. }\end{array}\right.$

$497 \quad T_{i}(k)=\left\{\begin{array}{lr}20^{\circ} \mathrm{C} & \text { if } 9 \leq \operatorname{hour}(k) \leq 18, \\ 18.5^{\circ} \mathrm{C} & \text { otherwise. }\end{array}\right.$

498 Once the tests were completed, the same weather data was then used in a simulated

499 environment in which the models of the building and equipment were the same as those

500 previously presented.

501 The simulated controller has to deal with the same mismatch in the weather prediction, but

502 there is no mismatch between the model used in the HMPC controller and the controlled

503 system.

\section{6.1 Cooling Test - Mechanical Ventilation Only}

505 This test was conducted between $6^{\text {th }}$ and $11^{\text {th }}$ of March 2015. To stay within the defined 506 comfort band, cooling was mostly required. The experimental and simulated indoor 507 temperature profiles, outdoor temperature, global horizontal radiation and the objective

508 temperature range are presented in Figure 10. In this test the daytime comfort band ended at $5095 \mathrm{pm}$ instead of $6 \mathrm{pm}$. One can notice that both the simulated and experimental controllers led

510 to the similar indoor temperature profiles, where it is noticeable the attempt to pre-cool the

511 building at the end of the night, and drift as much as possible inside the comfort band. The

512 reason behind this choice of the HMPC controller is that the most efficient cooling generation

513 came from the Direct PVT supply mode, especially at the end of each night, when the

514 temperature difference between the indoor and outdoor was greater. 


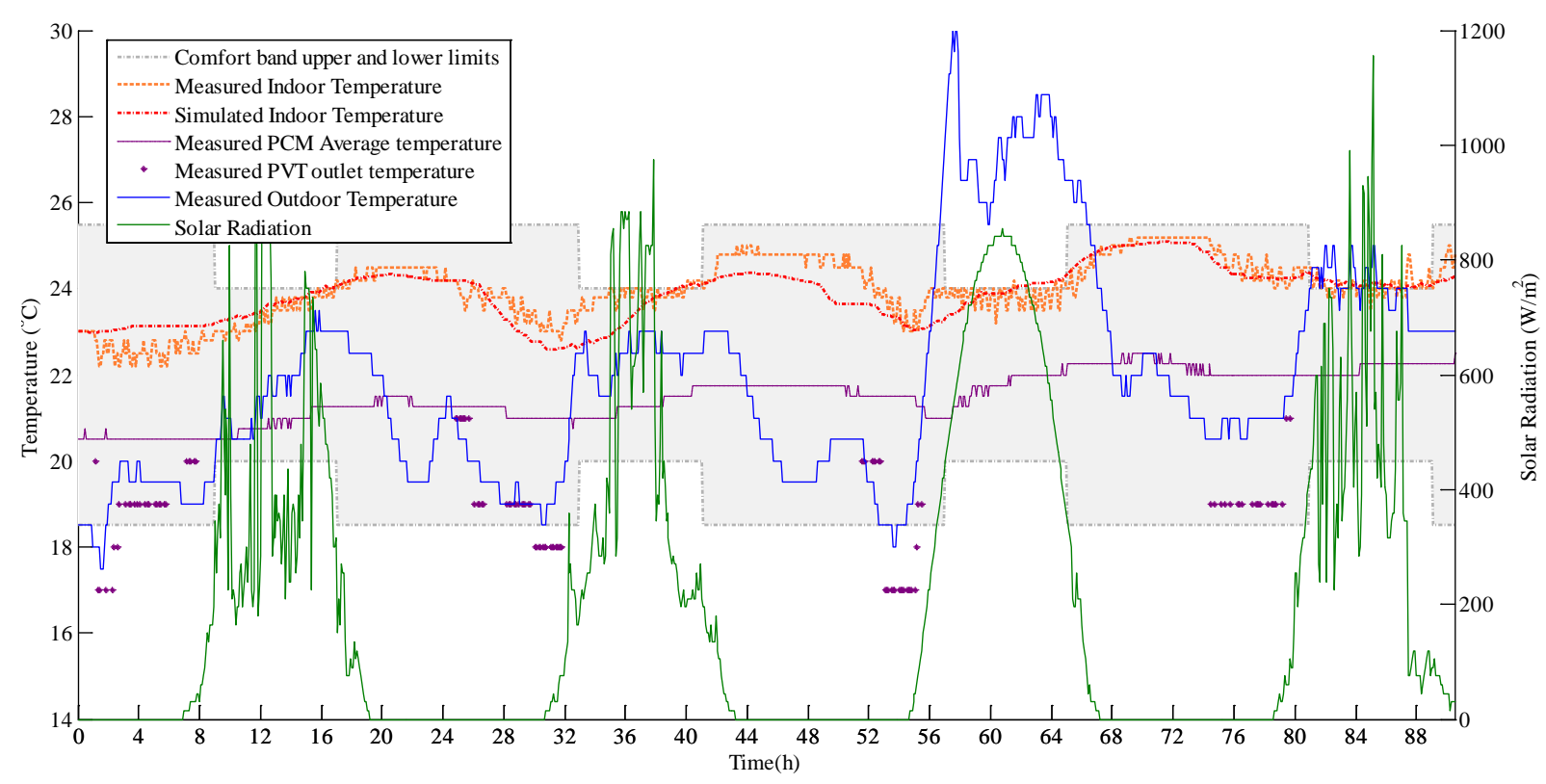

Figure 10: HMPC experimental test compared to the simulated test, HVAC only, March

517 2015: Temperature profiles and solar radiation.

518 When the pre-cooling provided by the PVT was not sufficient, the discharging of the PCM

519 unit and the normal air conditioner were compensating to keep the temperature inside the

520 comfort band. The profile of the activation of the various operating modes coinciding with

521 the activation of the three low-level controllers is presented in Figure 11. In this case it is

522 noticeable that both controllers tried to achieve their objectives with a similar sequence of the

523 selected operating modes with night time PVT Direct pre-cooling followed by a combination

524 of PCM Discharging and Normal Conditioning during the daytime. 


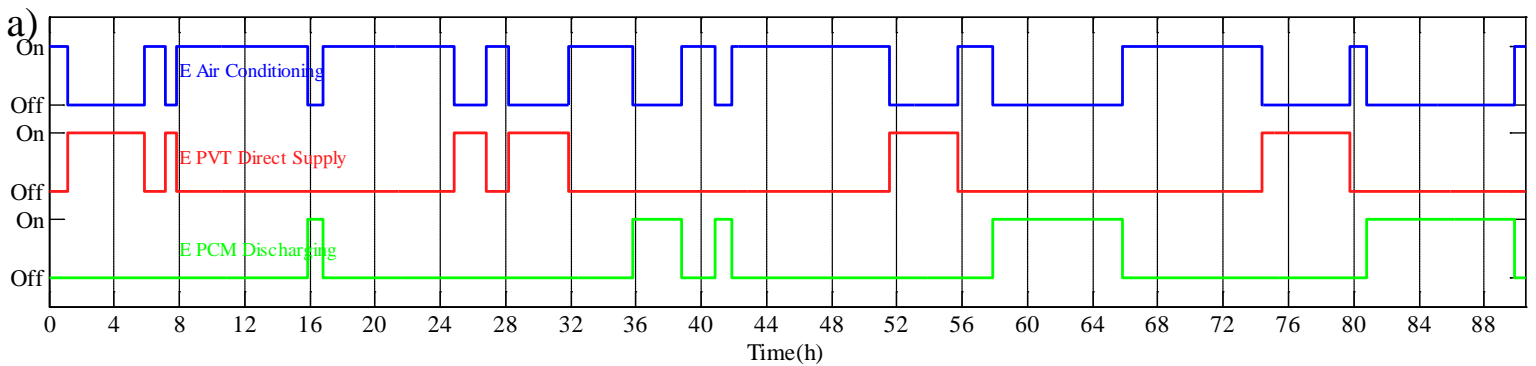

b)

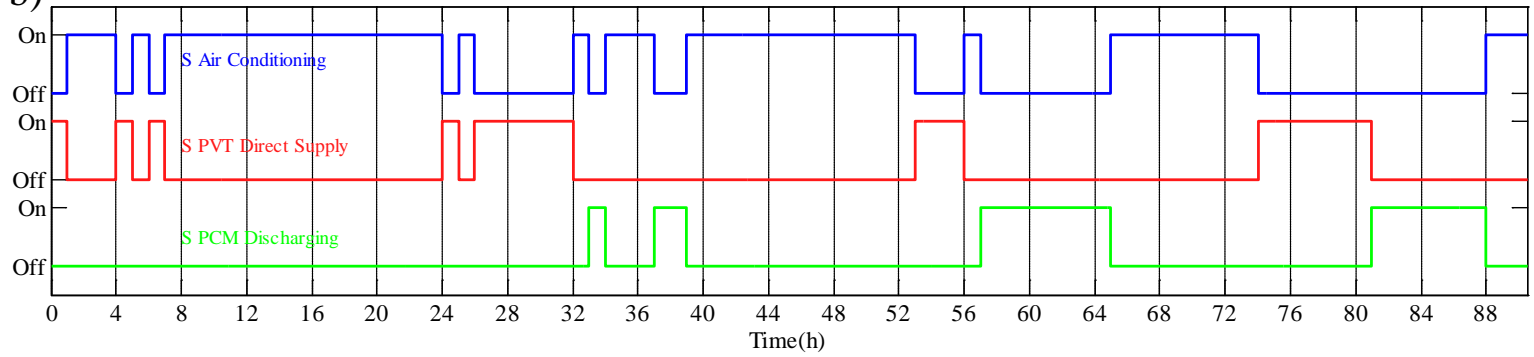

Figure 11: HMPC experimental test compared to the simulated test, HVAC only, March 2015: a) experimental and b) simulated test operating mode selection.

528 During the experimental test, the HVAC system provided a total of $45.2 \mathrm{kWh}$ of cooling to the building, among which $14.9 \mathrm{kWh}$ was from the PVT Direct Supply, $4.7 \mathrm{kWh}$ was from the PCM Discharging and $25.6 \mathrm{kWh}$ was from the use of the air conditioning unit. The average COP of the PVT system over the whole test, defined as the cooling provided divided by the electrical energy used by the fan, was 5.04, and the average COP of the PCM

533 Discharging was 4.48. In both cases, the controller can maintain the performance above the reference COP of the air conditioning system, identified to be 2.1 on average.

The simulated test generated the similar results, with a total of $41.2 \mathrm{kWh}$ of cooling provided to the building, among which the cooling provided the PVT, PCM unit and the air conditioning unit was 13.9, 4.7 and $22.6 \mathrm{kWh}$, respectively. The COP of the PVT system and

538 the PCM unit discharging was 4.59 and 4.55 respectively, higher than the reference COP.

539 The instantaneous experimental and simulated cooling generation and COP of the various operating modes are presented in Figure 12. 
541 It can be seen that the cooling of the house by both the PVT and PCM occurred in the similar

542 ways in the experimental and the simulated tests, keeping the instantaneous COP of the

543 system well above the given reference.

a)
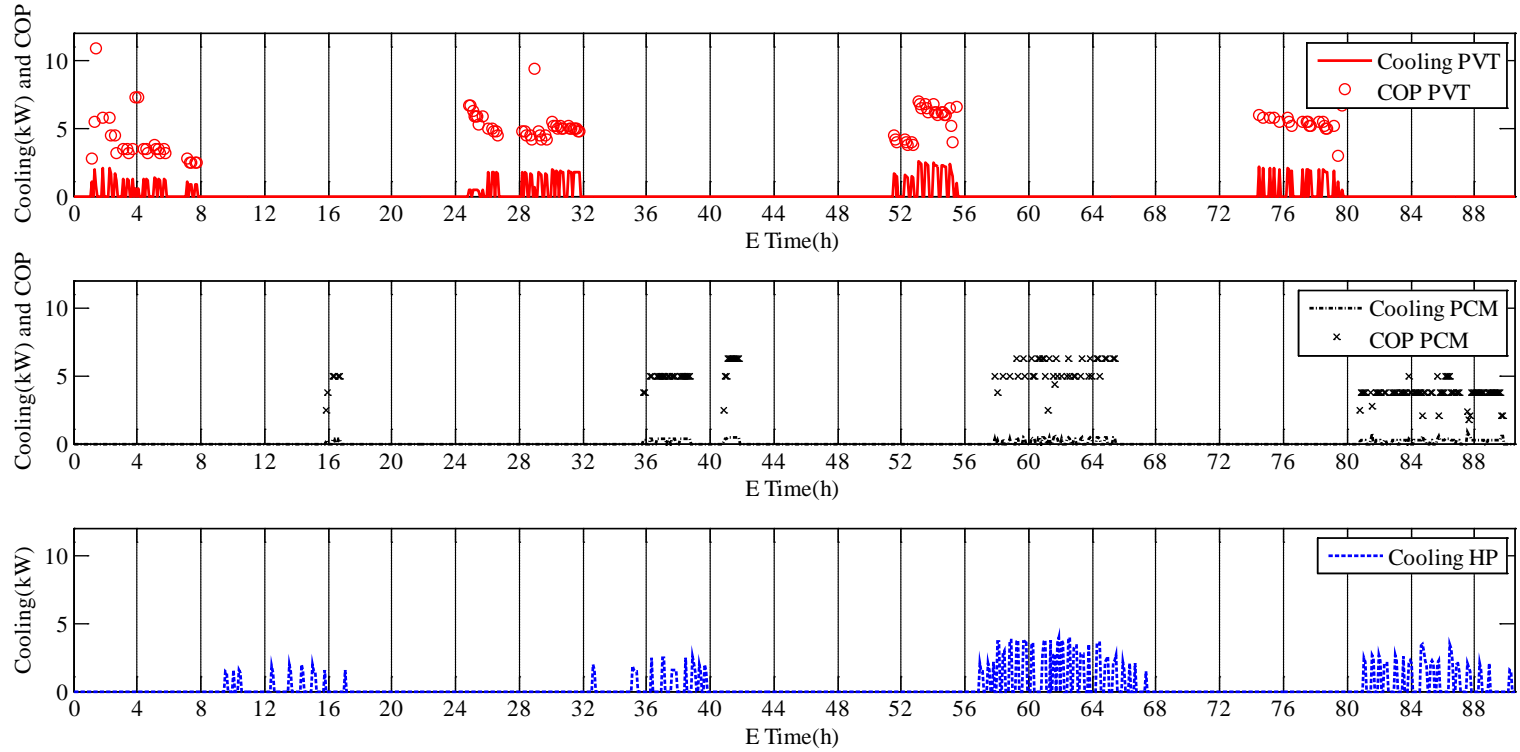

544

b)
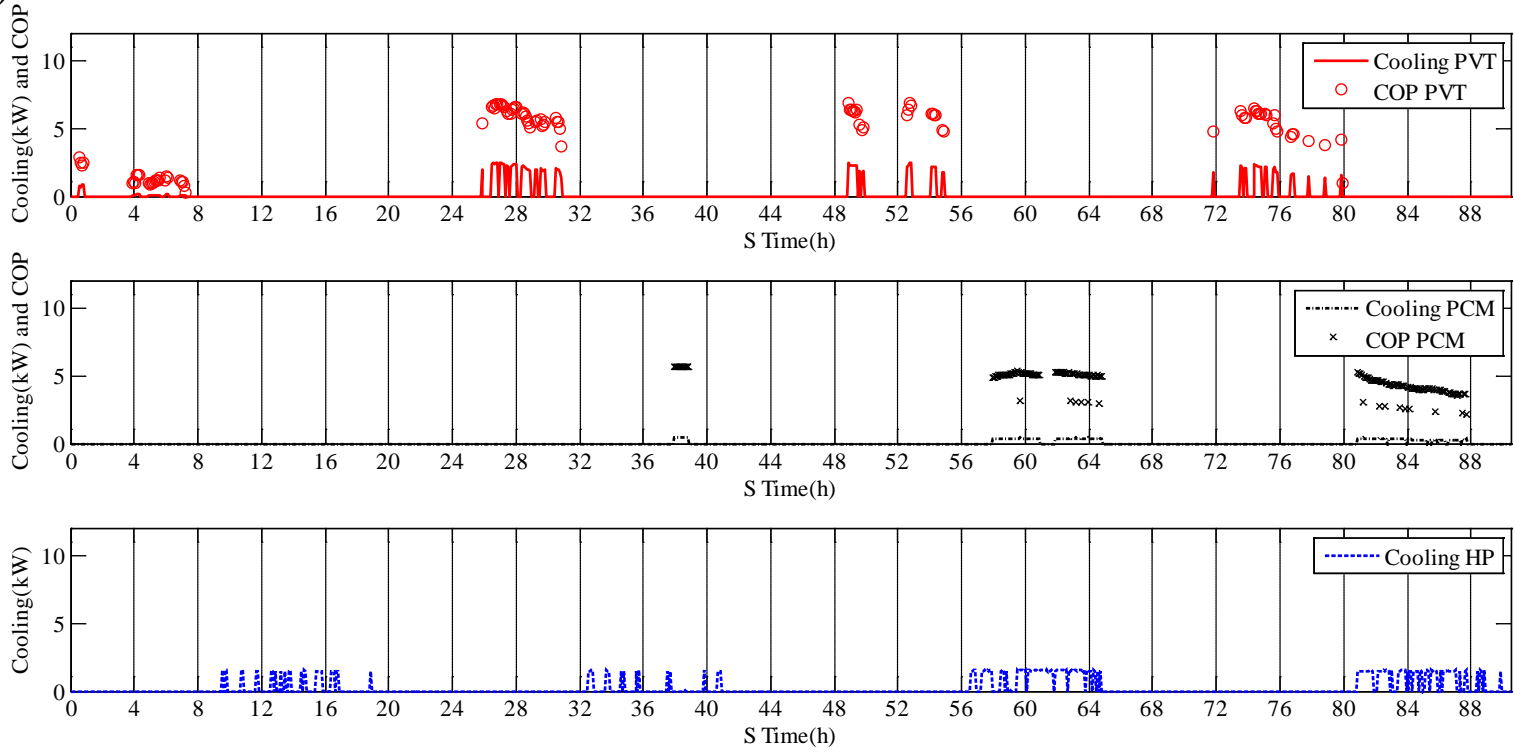

545

Figure 12: HMPC experimental test compared to the simulated test, HVAC only, March 2015: a) experimental and b) simulated instantaneous cooling generation and COP.

548 The overall performance of the experimental and simulated tests are also summarised in

Table 3. 
Table 3: Summary of the HVAC average performance, HMPC experimental and simulated test, HVAC only, March 2015.

\begin{tabular}{|c|c|c|c|}
\hline & Experimental & Simulated & Relative difference \\
\hline PVT Direct (kWh/day) & 3.97 & 3.71 & $6.5 \%$ \\
\hline Average COP PVT Direct & 5.04 & 4.59 & $8.9 \%$ \\
\hline PCM Discharge (kWh/day) & 1.25 & 1.25 & $0.0 \%$ \\
\hline Average COP PCM Discharge & 4.48 & 4.55 & $1.6 \%$ \\
\hline Normal Conditioning (kWh/day) & 6.82 & 6.03 & $11.6 \%$ \\
\hline $\begin{array}{c}\text { Total Electrical Consumption } \\
\text { (kWh/day) }\end{array}$ & 4.74 & 4.23 & $10.8 \%$ \\
\hline
\end{tabular}

\subsection{Cooling Test - Mechanical and Natural Ventilation}

555

A similar experiment was undertaken, using both the HVAC system and natural ventilation

very small so that their operation was the most preferable conditioning solution for the

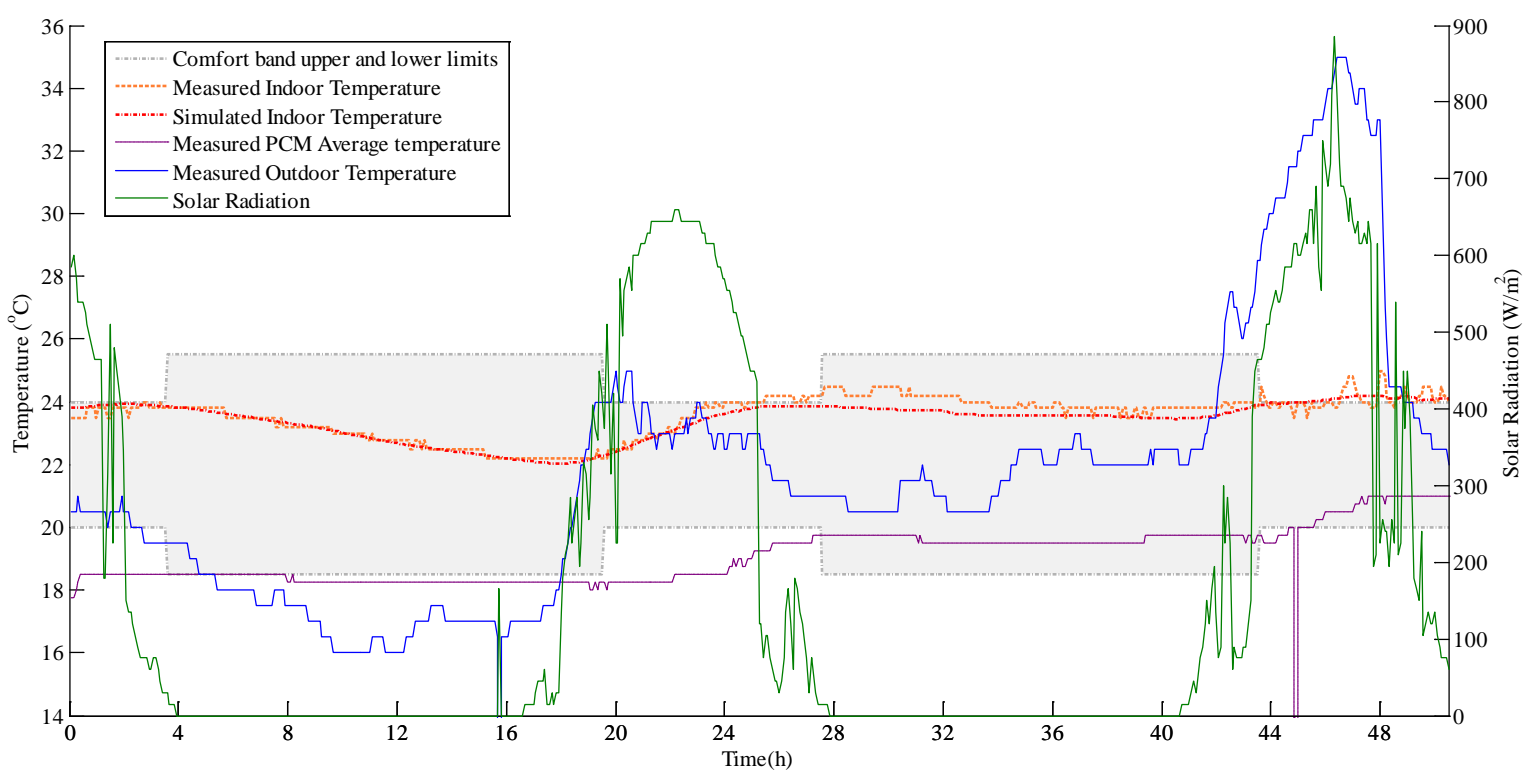

Figure 13: HMPC experimental test compared to the simulated test, HVAC and Natural Ventilation, April 2015: Temperature profiles and solar radiation.

563 The experimental and simulated indoor temperature profiles, outdoor temperature, global horizontal radiation and the objective temperature range are presented in Figure 13. It was be 
566 capable to effectively manage the indoor temperature even in very hot conditions. Compared

567 to the case where only the HVAC system was used, the Low-level Controller 3 was more 568 frequently used, since it is associated to both normal conditioning and natural ventilation 569 modes. The possibility to cool the building using natural ventilation was preferred by the 570 controller, since the cost associated to this mode is negligible compared to the other cooling 571 means. This behaviour of the controller can be observed in Figure 14 noting that mostly used 572 mode was Normal Conditioning and Natural Ventilation, by both the simulated and 573 experimental controllers. During this test PCM Discharging mode was only utilised at the end 574 of the second day (hours from 24 to 27 ) and during the third day (hours from 43 to 50 ). The 575 small difference between experimental and simulated operation is mostly due to a mismatch 576 between the model and the real system, and the need to correct the trajectory to keep the 577 temperature in the comfort band. The simulated controller activated the PVT direct supply for 578 a small portion of time at the end of the second night, whereas the experimental one used 579 natural ventilation, achieving a similar result in terms of remaining in the comfort band. It 580 can also be noted that this difference in operation is minimal if the results in Figure 15 are 581 observed, since a very small amount of cooling was provided via the Direct PVT mode. 
a)

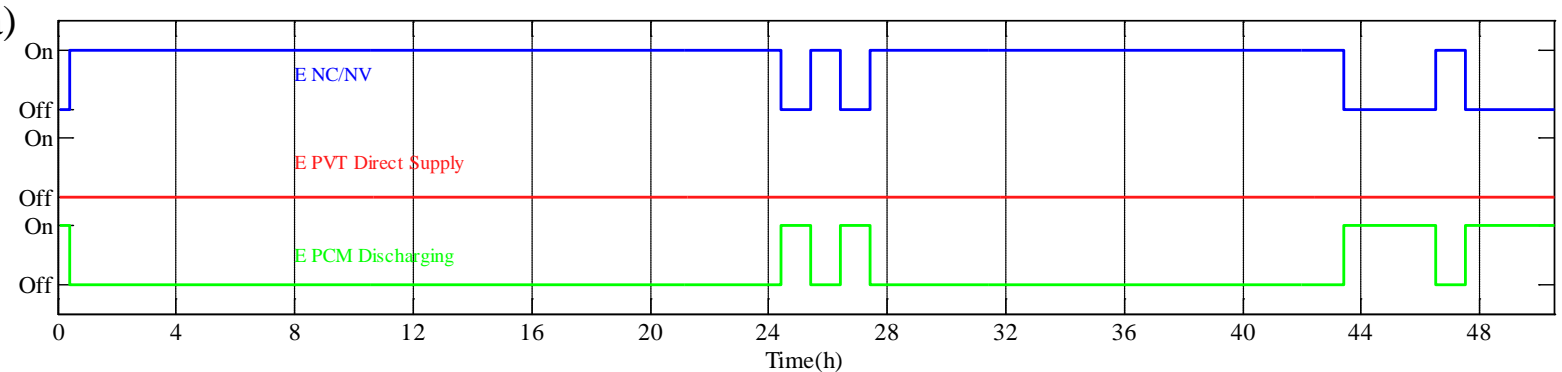

b)

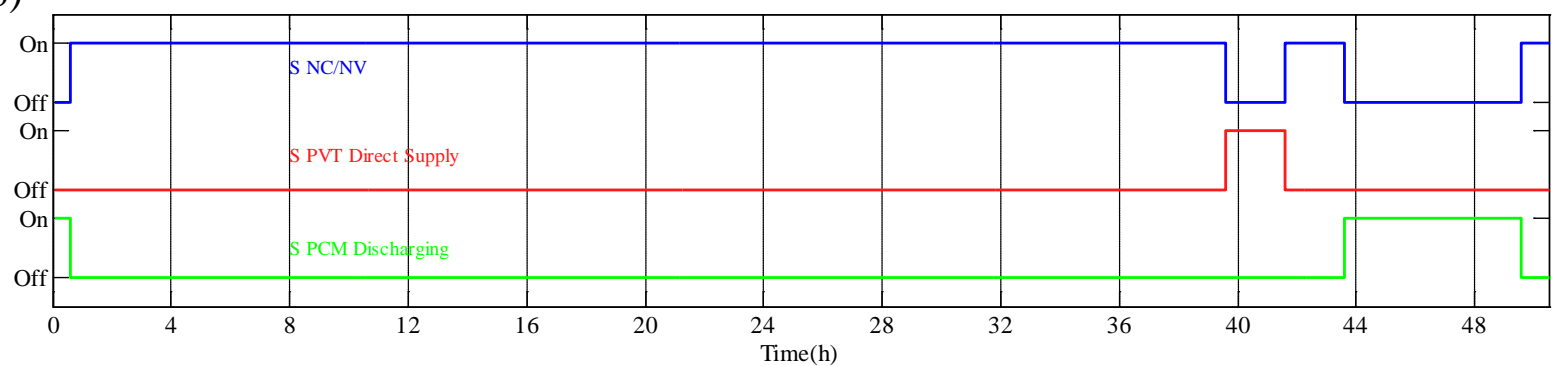

Figure 14: HMPC experimental test compared to simulated test, HVAC and Natural Ventilation, April 2015: a) experimental and b) simulated test operating mode selection.

585 During the experimental test the HVAC system provided a total of $12.9 \mathrm{kWh}$ of cooling to

586 the building, among which $4.9 \mathrm{kWh}$ was provided by discharging the PCM unit (at an average COP of 7.1) and $8.0 \mathrm{kWh}$ was supplied by using the air conditioning unit. Direct PVT mode was not used in the test. The natural ventilation mode kept the operable windows open for a total of 76 five minute control steps (i.e. 6 hours and 20 minutes) over the whole test (i.e. 50 hours and 30 minutes).

591 In the simulated test, the HVAC system provided $11.9 \mathrm{kWh}$ of cooling, among which 0.2 592 kWh was from Direct PVT mode (at an average COP of 3.1), $3.2 \mathrm{kWh}$ was supplied by discharging the PCM unit (at an average COP of 5.5), and $8.5 \mathrm{kWh}$ was provided by using

594 the air conditioning unit. During this simulated test, the Natural Ventilation mode was active

595 for 99 five minute control steps (8 hours and 15 minutes).The instantaneous experimental and

596 simulated cooling generation and COP under the various operating modes are presented in 597 Figure 15.

598 In this case, the experimental and simulated test resulted in a similar pattern in the utilisation 599 of the various resources. Natural Ventilation mode was often used during the night and 
600 during the day when the temperature was below the current indoor average temperature (e.g.

601 around hour 24). Both of the tests utilised PCM discharging during the last hot day, but it was

602 also utilised in the experimental test between hour 24 and hour 28 to correct the indoor

603 temperature trajectory.

a)
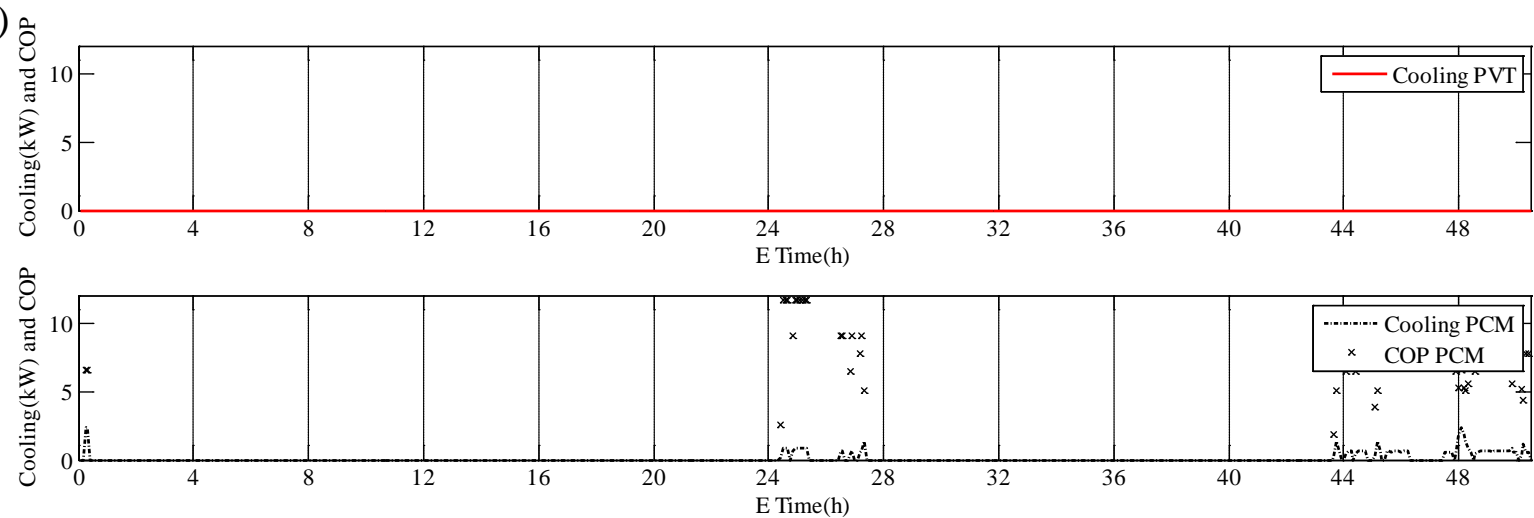

604

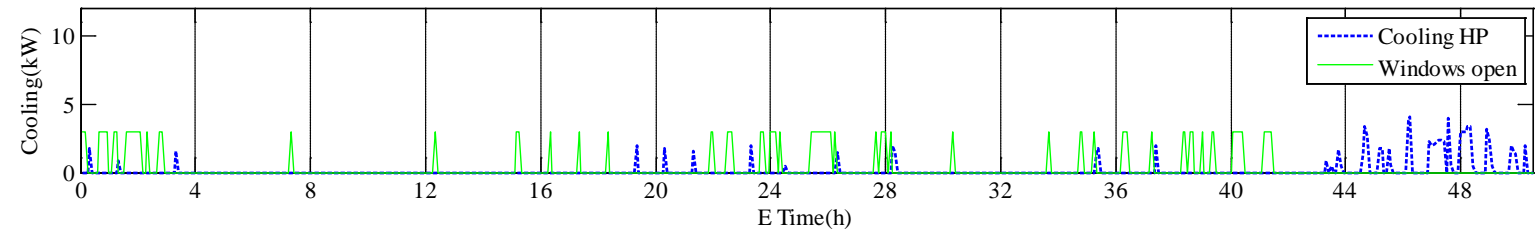

b)
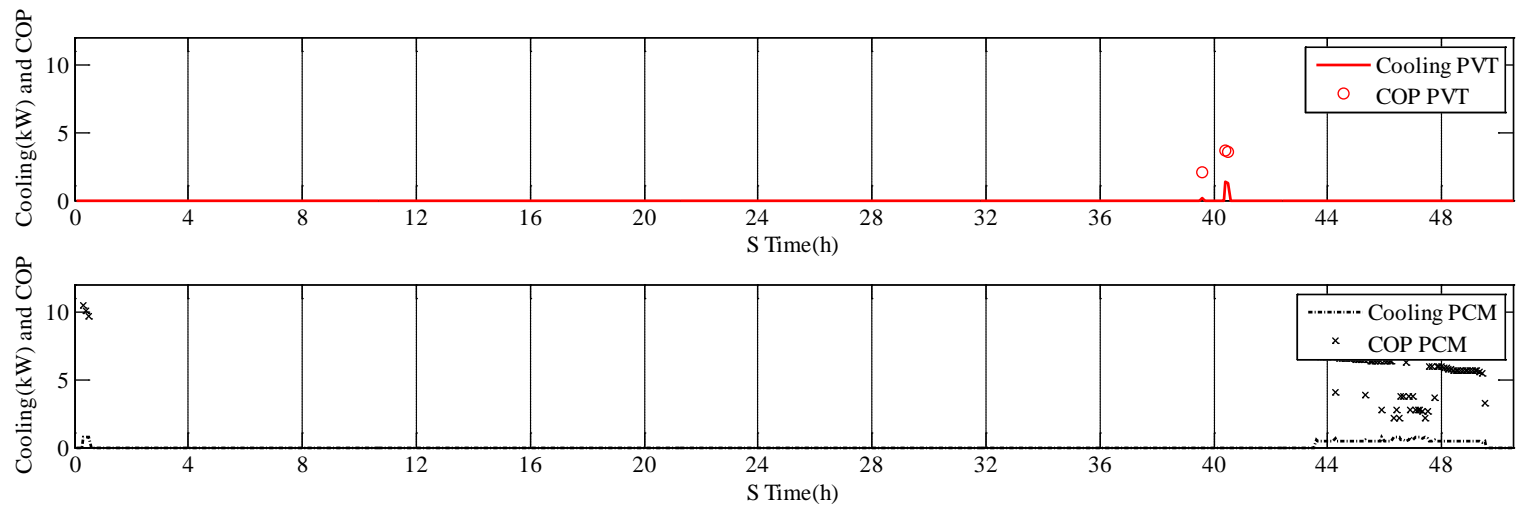

605

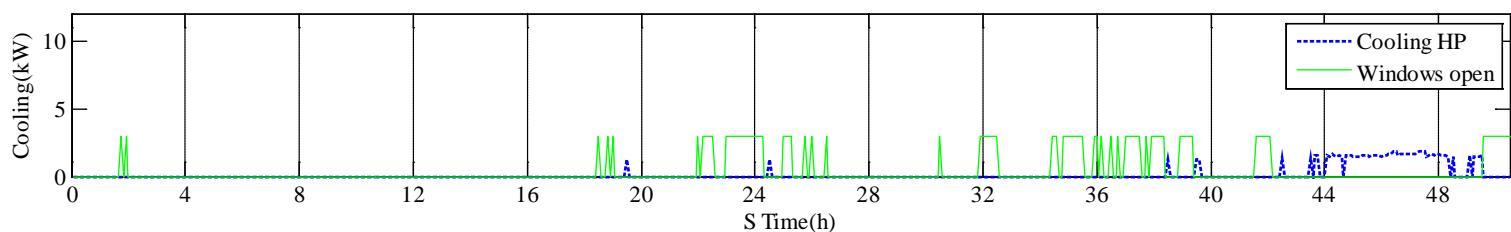

606 Figure 15: HMPC experimental test compared to the simulated test, HVAC and Natural Ventilation, 607 April 2015: a) experimental and b) simulated instantaneous cooling generation and COP.

608 The summary of the performance of the system in the experimental and simulated tests is 609 presented in Table 4. 
Table 4: Summary of the HVAC average performance, HMPC experimental and simulated test, HVAC and Natural Ventilation, April 2015.

\begin{tabular}{|c|c|c|c|}
\hline & Experimental & Simulated & Relative difference \\
\hline PVT Direct (kWh/day) & 0 & 0.10 & - \\
\hline Average COP PVT Direct & 0 & 3.10 & - \\
\hline PCM Discharge (kWh/day) & 2.35 & 1.54 & $34.5 \%$ \\
\hline Average COP PCM Discharge & 7.10 & 5.50 & $22.5 \%$ \\
\hline $\begin{array}{c}\text { Normal Conditioning } \\
\text { (kWh/day) }\end{array}$ & 3.84 & 4.08 & $6.3 \%$ \\
\hline $\begin{array}{c}\text { Total Electrical Consumption } \\
\text { (kWh/day) }\end{array}$ & 2.15 & 2.17 & $0.9 \%$ \\
\hline
\end{tabular}

612

\section{$613 \quad 7$ Conclusions}

614 This paper proposed a Hybrid Model Predictive Control (HMPC) strategy to manage a solar615 assisted HVAC system, retrofitted to a residential building. The system features a 616 Photovoltaic-Thermal (PVT) system and a phase change material (PCM) active storage unit, 617 integrated with a standard ducted air conditioning system. Comprehensive experimental 618 control infrastructure was designed, installed and commissioned in the Illawarra Flame 619 house, allowing the implementation of virtually any typology of control strategies to the 620 house system. An HMPC strategy with two levels of control was designed, implemented and 621 its operation demonstrated through both simulations and experiments. To understand the

622 effect of the mismatch between the models and the real system, the controller was simulated 623 using an identical model for both the controller and the system while introducing the same 624 error in the weather forecast.

625 The HMPC strategy shows an anticipative behaviour that could be noticed in the cooling 626 scenarios presented in this paper, where the HMPC pre-cooled the building utilising the fact

627 that bringing fresh air further cooled by the PVT system can lower the temperature of the 628 indoor air and building fabric more efficiently than the heat pump. The HMPC strategy also 629 demonstrated the value of using natural ventilation in both the experimental tests and 
simulated environment, by giving priority to window opening for cooling purposes whenever available.

632 The controller was able to keep the indoor temperature within the prescribed range, utilising the PVT and PCM storage to generate cooling at a higher COP than the reference standard air conditioner. The winter experiments highlighted the fact that appropriate insulation of an active PCM unit is crucial. Excessive heat losses prevented the system operated with efficient charging and discharging cycles.

637

Overall, the HMPC strategy demonstrated to be capable of effectively utilising the knowledge of the system future dynamics allowing it to manage well the available resources to maximise the efficiency of the system. The results presented in this paper show that the methodology proposed is implementable and promising. An important advantage of MPC techniques is that they enable the use of real-time measurements and forecasts to optimise the system performance when confronted with changing conditions and disturbances, which is particularly important when solar-driven generation is implemented on site and is only available at certain times of the day.

\section{Acknowledgements}

646 The authors would like to thank Prof. Alberto Bemporad and Dr. Daniele Bernardini for their 647 advice and help in the formulation of the control problem and its implementation in the Hybrid Toolbox.

\section{References}

650 [1] Kolokotsa D, Rovas D, Kosmatopoulos E, Kalaitzakis K. A roadmap towards intelligent net zero- and positive-energy buildings. Sol Energy 2011;85:3067-84. doi:10.1016/j.solener.2010.09.001.

653 [2] Mills E. Building Commissioning: A Golden Opportunity for Reducing Energy Costs and Greenhouse Gas Emissions. 2009.

655 [3] Lu Y, Wang S, Shan K. Design optimization and optimal control of grid-connected 
665

666

667

668

669

670

671

672

673

674

675

676

677

678

679

680

681

682

683

684

685

686

687

688

689

690

691

692

693

694

695

696

697

and standalone nearly/net zero energy buildings. Appl Energy 2015;155:463-77. doi:10.1016/j.apenergy.2015.06.007.

[4] ASHRAE. 2013 ASHRAE Handbook - Fundamentals (SI Edition). American Society of Heating, Refrigerating and Air-Conditioning Engineers, Inc.; 2013.

[5] ASHRAE. 2015 ASHRAE handbook - HVAC Applications. 2015. American Society of Heating, Refrigerating and Air-Conditioning Engineers, Inc..

[6] Armstrong P, Leeb S, Norford L. Control with building mass-Part I: Thermal response model. ... -American Soc ... 2006;112. doi:10.1016/j.apenergy.2007.08.001.

[7] Armstrong P, Leeb S, Norford L. Control with building mass-Part II: Simulation. Ashrae Trans 2006;112. doi:10.1016/j.apenergy.2007.08.001.

[8] Gwerder M, Lehmann B, Tödtli J, Dorer V, Renggli F. Control of thermally-activated building systems (TABS). Appl Energy 2008;85:565-81. doi:10.1016/j.apenergy.2007.08.001.

[9] Kim SH. An evaluation of robust controls for passive building thermal mass and mechanical thermal energy storage under uncertainty. Appl Energy 2013;111:602-23. doi:10.1016/j.apenergy.2013.05.030.

[10] Siroky J, Oldewurtel F, Cigler J, Privara S. Experimental analysis of model predictive control for an energy efficient building heating system. Appl Energy 2011;88:3079_ 87. doi:10.1016/j.apenergy.2011.03.009.

[11] Prívara S, Váňa Z, Žáčeková E, Cigler J. Building modeling: Selection of the most appropriate model for predictive control. Energy Build 2012;55:341-50. doi:10.1016/j.enbuild.2012.08.040.

[12] Afram A, Janabi-Sharifi F. Gray-box modeling and validation of residential HVAC system for control system design. Appl Energy 2015;137:134-50. doi:10.1016/j.apenergy.2014.10.026.

[13] Bacher P, Madsen H. Identifying suitable models for the heat dynamics of buildings. Energy Build 2011;43:1511-22. doi:10.1016/j.enbuild.2011.02.005.

[14] Malisani P, Chaplais F, Petit N, Feldmann D. Thermal building model identification using time-scaled identification methods. 49th IEEE Conf Decis Control 2010:308-15. doi:10.1109/CDC.2010.5717975.

[15] Privara S, Vana Z, Gyalistras D, Cigler J, Sagerschnig C, Morari M, et al. Modeling and identification of a large multi-zone office building. 2011 IEEE Int Conf Control Appl 2011:55-60. doi:10.1109/CCA.2011.6044402.

[16] Zacekova E, Privara S, Vana Z. Model predictive control relevant identification using partial least squares for building modeling. Aust Control Conf (AUCC), 2011 2011:422-7.

[17] Zhao Y, Lu Y, Yan C, Wang S. MPC-based optimal scheduling of grid-connected low energy buildings with thermal energy storages. Energy Build 2015;86:415-26. doi:10.1016/j.enbuild.2014.10.019.

[18] Lu Y, Wang S, Sun Y, Yan C. Optimal scheduling of buildings with energy generation and thermal energy storage under dynamic electricity pricing using mixed-integer nonlinear programming. Appl Energy 2015;147:49-58. 
doi:10.1016/j.apenergy.2015.02.060.

[19] Kashima T, Boyd SP. Cost optimal operation of thermal energy storage system with real-time prices. 2013 Int Conf Control Autom Inf Sci ICCAIS 2013 2013:233-7. doi:10.1109/ICCAIS.2013.6720560.

[20] Touretzky CR, Baldea M. Integrating scheduling and control for economic MPC of buildings with energy storage. J Process Control 2014;24:1292-300. doi:10.1016/j.jprocont.2014.04.015.

[21] Berkenkamp F, Gwerder M. Hybrid model predictive control of stratified thermal storages in buildings. Energy Build 2014;84:233-40. doi:10.1016/j.enbuild.2014.07.052.

[22] Rodriguez M, De Prada C, Capraro F, Cristea S, De Keyser R. Hybrid Predictive Control of a Solar Air Conditioning Plant. Eur J Control 2008:1-15. doi:10.3166/EJC.14.1.

[23] Siroky J. Hybrid MPC approach to reconfiguration of building heating system. Eur Control Conf 2013:2675-80.

[24] Lindel D, Afshari H, Alisafaee M, Biswas J, Caban M, Mocellin X, et al. Field tests of an adaptive, model-predictive heating controller for residential buildings. Energy Build 2015;99:292-302. doi:10.1016/j.enbuild.2015.04.029.

[25] Di Giorgio A, Liberati F. Near real time load shifting control for residential electricity prosumers under designed and market indexed pricing models. Appl Energy 2014;128:119-32. doi:10.1016/j.apenergy.2014.04.032.

[26] Fiorentini M, Cooper P, Ma Z, Robinson DA. Hybrid model predictive control of a residential HVAC system with PVT energy generation and PCM thermal storage. Energy Procedia 2015;83:21-30. doi:10.1016/j.egypro.2015.12.192.

[27] Bemporad A, Morari M. Control of systems integrating logic, dynamics, and constraints. Automatica 1999;35:407-27. doi:10.1016/S0005-1098(98)00178-2.

[28] Bemporad A. Hybrid Toolbox User ' s Guide 2012: Available at: http://cse.lab.imtlucca.it/ bemporad/hybrid/toolbox/.

[29] Fiorentini M, Cooper P, Ma Z. Development and optimization of an innovative HVAC system with integrated PVT and PCM thermal storage for a net-zero energy retrofitted house. Energy Build 2015;94:21-32. doi:10.1016/j.enbuild.2015.02.018.

[30] OASIS. oBIX 2015. http://www.obix.org/ (accessed August 28, 2015).

[31] Gurobi. Available at: http://www.gurobi.com/ (accessed August 28, 2015).

[32] Mathworks. Matlab System Identification Toolbox 2015.

[33] Ljung L. Ljung L System Identification Theory for User.pdf. PTR Prentice Hall Up Saddle River NJ 1987;25:475-6. doi:10.1016/0005-1098(89)90019-8.

[34] PCM Products. Available at: http://www.pcmproducts.net/ [Accessed August 28, 2015].

[35] Fiorentini M, Cooper P. Experimental Investigation of an Innovative HVAC System with Integrated PVT and PCM Thermal Storage for a Net-Zero Energy Retrofitted House. ASHRAE Winter Confrence, Chicago, 2015. 
[36] Bemporad A. Model predictive control design: New trends and tools. Proc 45Th Ieee Conf Decis Control Vols 1-14 2006:6678-83. doi:10.1109/CDC.2006.377490.

741

[37] Ren MJ, Wright J a. Adaptive Diurnal Prediction of Ambient Dry-Bulb Temperature and Solar Radiation.

Res

2002;8:383-401. doi:10.1080/10789669.2002.10391297. 